\title{
Punching Behaviour of Column-slab Connection Strengthened with Non- Prestressed or Prestressed FRP plates
}

\author{
A. Abdullah ${ }^{\mathrm{a}, \mathrm{b}}$ and C. G. Bailey ${ }^{\mathrm{c}}$ \\ ${ }^{a}$ Faculty of Engineering, Aswan University, 81542 Aswan Egypt. \\ ${ }^{\mathrm{b}}$ Faculty of Engineering, Bisha University, $\mathrm{P}$ O Box 551, KSA. \\ ${ }^{c}$ School of Mechanical, Aerospace and Civil Engineering, University of Manchester, \\ Sackville Street, Manchester, P O Box 88, UK
}

\begin{abstract}
Fracture resistance of concrete column-slab connections, with low reinforcement ratios and strengthened by carbon fibre reinforced polymer (CFRP) plates, is often governed by debonding failure modes. In this paper, a three-dimensional finite element model is conducted to predict the punching behaviour of concrete column-slab connections which incorporate bonded non-prestressed and prestressed CFRP plates to the tension surface of the slab. The adopted interfacial behaviour, between the FRP materials and concrete, takes into account the effect of mixed mode behaviour on the displacement fields at the critical diagonal cracks (CDC). Results are then presented in terms of the ultimate load capacities, load-strain relationships in the FRP and internal steel reinforcement, load-interfacial stress relationships, and stress distributions in the FRP reinforcement. It can be stated that by adopting the mixed mode behavior at the interface between the fibres and concrete, the onset of debonding is effectively captured by the FE analysis, which is very difficult in a laboratory test.
\end{abstract}

Keywords: prestressed FRP, debonding, finite element analysis.

\section{Introduction}

Existing concrete flat slabs may need to be strengthened due to insufficient punching shear capacity, as a result of changing the building use, new openings in a slab, design or construction errors. Several investigations have been conducted on strengthening the column-slab connection by different techniques to delay or prevent punching shear failure. These techniques, so far, can be categorized into two main approaches; direct shear strengthening and flexural shear strengthening. In the former approach, FRP composites are threaded through the thickness of the slab; in a similar method to the application of shear studs as a transverse reinforcement, to carry the diagonal tension forces [1, 2]. However, in the second approach FRP laminates are bonded; as flexural reinforcement, to the tension surface of the slab [3-5]. This last one is easy to implement and efficient, especially for slabs with low-reinforcement ratios.

The punching behaviour of RC slabs strengthened with externally bonded reinforcement (EBR) during the new service life is relatively complicated because of the structural complexity and the progress of both loads and cracks. To attain the ultimate loading capacity of such strengthened slabs, the composite action has to be maintained. That is the EBR contributes to the flexural strength, which indirectly enhance the punching capacity of the strengthened slab [6]. Yet, the CDC induced interfacial debonding, is considered one of the most common failure modes responsible for loss of composite action of RC slabs strengthened with EBR. This mode of failure occurs; near the column area, when the shear capacity of the section is exceeded prior to the load level 
reaching the flexural strength. The development of such diagonal shear crack in flat slabs is associated with both horizontal and vertical openings [7]. Hence, the change in the displacement fields at the interface level; around the crack mouth, affects the bonding behaviour $[8,9]$.

Two-main analysis approaches can be adopted in analysing FRP-RC composite sections; the classical analysis theories and the numerical analysis. The first approach, which is adopted in most of the available codes [10-13] for FRP strengthening applications, involves solutions of 'simple' design equations based on closed form solutions [14]. These formulae are usually accompanied with some provisions to control deflection and cracking. The applicability of this method is limited to certain geometries and loading configurations. Thus, it is not applicable to non-conventional slab design in some cases; for example, a slab strengthened with EBR or a slab with internal openings. An acceptable approach to overcome such shortcomings is to impose some modifications to the steel RC design practice for the design of RC slabs strengthened with EBR. The main assumptions adopted in this approach are; a) no slip between the external FRP and the concrete substrate, b) premature separation and shear failure of the FRP is not admissible and c) tensile strength of the adhesive can be ignored (i.e. bond line is thin).

The finite element analysis (FEA) may, therefore, provide a more reliable and accurate method to predict the behaviour of slabs strengthened with EBR in both the serviceability and ultimate limit state. It enables accounting for different debonding failure modes if the bond interface is modelled properly. Generally, two approaches are available for modelling the bond interface in FRP-strengthened reinforced concrete structures. The first one is the meso-scale FEA, in which the FRP nodes are directly connected to the adjacent concrete nodes. In this approach a fixed angle crack model (FACM) is employed in conjunction with a very fine finite element mesh with element sizes being one order smaller than the thickness of the facture layer of concrete. This method was recently developed by $\mathrm{Lu}$ et al. [15] and was able to give accurate predictive results for the FRP-concrete bonded joints. In the second approach, which is more suitable for large structures and 3D FEA, a layer of interface elements between the FRP and the concrete is employed. In this case, the debonding is simulated as failure of the interface elements rather than a failure of the very fine finite element mesh adjacent to the FRP plate in the first approach.

Experimental investigation on column-slab connections, with low reinforcement ratio, and strengthened with non-prestressed or prestressed CFRP plates have been conducted, of which results have been published before by the authors [16]. In this study, a threedimensional finite element model is developed to provide a further insight into the punching behaviour of such column-slab connections. The interfacial debonding behaviour between the FRP and concrete is modelled, considering the change in the displacement fields due to the development of the CDC. Results are presented herein in terms of the load deflection relationships, failure modes, ultimate load capacities, stresses in the steel reinforcements and CFRP plates, and interfacial slip and stress distributions. The numerical predictions are compared with test data and good agreement has been obtained.

\section{Summary of experimental study}


Five specimens were designed and fabricated to simulate interior column-slab connections. The test specimens were $1800 \times 1800 \times 150 \mathrm{~mm}$ square slabs with a stub column, $250 \times 250 \times 142 \mathrm{~mm}$ at the centre of the slab that was monolithically cast with the slab, as shown in fig. 1 . The characteristic compressive strength of concrete was $35 \mathrm{MPa}$. All specimens were reinforced with 8 No.12mm diameter bars in each direction giving a reinforcement ratio of $0.33 \%$. The tensile test of the reinforcing bars indicated that the measured yield and the ultimate strengths were 579 and $650 \mathrm{MPa}$, respectively. Four slabs out of five were strengthened with non-prestressed and prestressed CFRP plates bonded to the tension surface of concrete substrate. The ultimate tensile strength and the modulus of elasticity of the plates in the fibre direction were 2,970 and 172,000 $\mathrm{MPa}$. For the prestressed slabs, different values of pre-stressing forces were introduced to the CFRP plates to examine the effect of the prestressing ratio on the punching behaviour of such connections. The prestressing forces were limited by the creep rupture strength of the FRP plate which is $55 \%$ of its ultimate tensile strength; according to ACI Committee 440 [11]. The prestressing device shown in fig. 2 was developed to apply the prestressing forces. To simulate precracked slabs due to ageing or overloading conditions a notch of $12 \mathrm{~mm}$ depth was introduced for all specimens at the critical section; two times the slab depth $d$ from the column face, according to Eurocode 2 [17]. Table 1 presents a brief description of test specimens, while the subscript numbers denote the effective residual prestressing ratio.

All specimens were loaded concentrically, and were simply supported along all four edges with the corner free to lift, as shown in fig. 1. Equally spaced linear variable deferential transformers (LVDTs) were placed on the top surface of one eighth of the specimen to measure the deflection profiles of the specimen during the application of load, as shown in fig. 3. High-precision LVDTs were used to measure the crack mouth opening displacement during the test. Strain gauges were mounted along each direction to measure the strains of the FRP sheets and steel bars to provide additional strain information. Further details of the experimental programme can be found in reference [16].

\section{Finite element analysis}

The specimens under investigation represent the region of negative bending around an interior column-slab connection up to the points of contraflexure. This loading condition has two planes of symmetry; XZ and YZ, as shown in fig. 2. Accordingly, only a quarter of the slab was modelled.

In this study, finite element software [18] was used to model the concrete slabs, adopting a discrete modelling approach. A typical slab model is shown in fig. 4. Eightnode isoparametric brick elements were adopted to model the concrete. To represent the internal steel reinforcement, two-node linear displacement truss element was used. Perfect bond between the grid reinforcement and the surrounding concrete material was assumed. This was considered reasonable because ribbed and bent bars were used in the tests. A conventional layered shell element was chosen to model the FRP reinforcement. This is based on the assumption that the loading configuration is most likely to produce in-plane stresses in FRP, so that the out-of-plane normal stress component is zero. Consequently, FRP could be modelled as an anisotropic homogeneous material under plane stress. 
The FRP-concrete interface was modelled using a two-node connector element. The connectivity of this element could be simplified since it combines three springs working orthogonally. Two springs out of three were assumed to be working in the local first and second directions (the first and second shear direction), while the third one was applied in the out-of-plane direction (normal direction) between the concrete and FRP plates. The four-node rigid surface element was chosen to model the supports. Each node has three degrees of freedom. All elements were connected to a reference point where the boundary conditions were applied.

To verify the model, mesh sensitivity was investigated against both the reference slab $\left(\mathrm{RS}_{0}\right)$ and the strengthened slab $\left(\mathrm{RS}-\mathrm{F}_{0}\right)$ in order to cover the range of reinforcement ratio. Different mesh sizes of $75 \mathrm{~mm}, 50 \mathrm{~mm}, 30 \mathrm{~mm}$ and $25 \mathrm{~mm}$ were considered in the sensitivity analysis so that the tension stiffening overshadows softening of concrete. The mesh was said to be converged when an increase in the mesh density had a negligible effect on the results obtained, while the load-midspan deflection response was the reference parameter in determining the appropriate mesh size. The convergence study implied that the $50 \mathrm{~mm}$ mesh size converged to both the $30 \mathrm{~mm}$ and $25 \mathrm{~mm}$ mesh sizes. On the other hand the $75 \mathrm{~mm}$ mesh appeared to have unstable behaviour after cracking and to experience numerical problems. Therefore, it was decided to adopt the $50 \mathrm{~mm}$ average mesh size for the analysis.

\subsection{Material modelling}

\subsubsection{Concrete}

A damaged plasticity model was used for the analysis of the concrete slabs [18]. The model makes use of the yield function of Lubliner et. al. [19], with the modifications proposed by Lee and Fenves [20] to account for different evolution of strength under tension and compression. Structural aspects of the rebar-concrete interaction, like bondslip and dowel action, are indirectly considered by introducing some "tension stiffening" into the concrete softening behaviour to simulate load transfer across cracks through the rebar.

Figure 5 shows the uniaxial stress-strain relationship of concrete adopted in this study. For concrete under compression, the material model specified in Eurocode 2, Part 1.1 [17], was modified to include the initial linear elastic response up to $40 \%$ of the mean compressive strength. The mean compressive strength $\left(f_{c m}=f_{c k}+8\right)$ of concrete was taken as the peak compressive strength, where $f_{c k}$ is the characteristic compressive strength of concrete.

For concrete under tension, a smeared crack model along with the Scanlon approach [21] for tension softening after cracking was adopted (refer to fig. 5). The tensile strength was taken as the lower bound defined in Eurocode 2 [17]; $f_{c t k \text {, min }}=0.21 f_{c k}^{(2 / 3)}$. The tension stiffening effect vanishes at a strain level, $\varepsilon_{0}=\alpha \varepsilon_{c k}$, where $\alpha$ is a factor which depends on the reinforcement ratio, bond characteristics, dimensionality of the problem and whether the ultimate load is reached before or through the yielding of reinforcement. In this study, the adopted values of $\alpha$ ranged from 10-25.

\subsubsection{Steel reinforcement and FRPs}


The steel reinforcement was defined based on the stress-strain results of the uniaxial tensile tests given in reference [16]. The behaviour was defined as a bi-linear curve (linear elastic with strain hardening). The elastic modulus of the steel reinforcement ranged between 190 and $192 \mathrm{GPa}$. The yield stress ranged between 570 and $576 \mathrm{MPa}$. A linear elastic orthotropic constitutive relation was assumed for the CFRP plates. The elastic longitudinal modulus, $E_{x}$, and tensile strength for the CFRP plates were provided by the manufacture and checked experimentally [16]. The other material properties of the CFRP plates such the elastic modulus in the direction perpendicular to the fibres, $E_{y}$, and shear modulus, $G_{x y}$, were assumed according to typical material properties published in Kollár and Springer [22]. A summary of the material properties of the FRP plates is shown in Table 2.

\subsubsection{FRP-concrete interface}

To simulate the interfacial behaviour a force-displacement model was used; cited in [18]. A linear elastic behaviour followed by the initiation and evolution of damage was assumed. The elastic behaviour is written in terms of an elastic constitutive matrix that relates the force to the displacement across the interface. The force vector, $f$, consists of three components: $f_{n}, f_{s}$, and $f_{t}$, which represents the normal (along the local $z$ direction) and the two shear forces (along the local $x_{\text {- }}$ and ${ }^{y}$-directions), respectively.

The corresponding displacements are denoted by $\delta_{n}, \delta_{s}$, and $\delta_{t}$. No interaction was considered between mode I and mode II cracking. Thus, the elastic behaviour can be written as follows:

$\mathrm{f}=\left\{\begin{array}{l}f_{n} \\ f_{s} \\ f_{t}\end{array}\right\}=\left[\begin{array}{lll}k_{n n} & 0 & 0 \\ 0 & k_{s s} & 0 \\ 0 & 0 & k_{t t}\end{array}\right]\left\{\begin{array}{l}\delta_{n} \\ \delta_{s} \\ \delta_{t}\end{array}\right\}=K \delta$

Damage of the interface layer was assumed to initiate when the peak value of the forces is reached in any direction. Once the damage initiation criterion was met, an exponential damage evolution law was then applied; Chen and Teng's model [23] was used for the two shear components, while an equivalent uniaxial concrete behaviour was used in the normal direction (refer to fig. 5). Figure 6 shows the interfacial stress-slip curve for the bond interface, whereas the tensile strength, $f_{c t k \text {,min }}$, is evaluated according to Eurocode 2 [17].

\subsection{Loading and boundary conditions}

The load history for the FE model represented the actual loading scheme in the actual experiments. It comprised three main steps for the non-prestressed slabs, while an additional forth step was needed for prestressed slabs, as follows:

i. Establish contact: the supports were modelled as a rigid surface to distribute the load over the supporting area and to allow the slab corners to lift up;

ii. Release constraints: this step is a consequence of the previous step;

iii. Prestressing step: is a step where the prestressing force is applied to slab through the FRP plates; 
iv. Loading: is displacement-based until failure occurred, while the upper limit of the displacement values were chosen so that the entire load-deflection plateau, including pre- and post-failure regions, can be captured.

The perimeter of the slab was simply supported, without any horizontal restraint, and the corners are free to lift as shown in fig. 2. In order to represent these boundary conditions in the slab model, the planes of symmetry; XZ and YZ, were assumed to be horizontally restrained in the $\mathrm{Y}$ and $\mathrm{X}$ directions respectively, and a rigid surface supports the slab perimeter over a distance of $1600 \mathrm{~mm}$ into the slab. Such representation of boundary conditions enabled good capture of the stress state around the column area.

\section{Results}

\subsection{Load-deflection and failure characteristics}

As shown in fig. 7, it can be seen that the model provided good correlation, up to the failure load recorded in the test, for the load-deflection relationship for the nonprestressed slab (RS- $\left.\mathrm{F}_{0}\right)$. However, a stiffer behaviour was noticed for the FE model for the slab $\left(\mathrm{RS}_{0}\right)$ up to a deflection of $15 \mathrm{~mm}$. That is the deflection predicted by the FE analysis is based on a smeared cracking approach which does not account for the additional deflection resulting from rotation of the slab about CR, as shown in fig. 8. That is flexural deflection is a result of curvature within the member. Nevertheless, for the strengthened slab $\left(R S-F_{0}\right)$ the additional FRP reinforcement alleviated the discontinuity in the member rotation at the critical shear crack region which in turn reduced the amount of deflection resulting from slab rotation.

For the prestressed slabs, the deflection predicted by the FE model compares very well with the measured deflection up to failure, as well. It is clear that the confinement effect of the prestressing forces resulted in more stiff behaviour than both slab $\left(\mathrm{RS}_{0}\right)$ and $(\mathrm{RS}-$ $F_{0}$ ). This stiff behaviour was for higher load levels, as shown in fig. 7. The overall behaviour can be simplified by a bilinear trend. The behaviour of the 30\%-prestressed slab (RS- $\mathrm{F}_{30}$ ) resembles, to some extent, the behaviour of the 7\%-prestressed slab (RS$\left.\mathrm{F}_{7}\right)$ and $15 \%$-prestressed slab $\left(\mathrm{RS}-\mathrm{F}_{15}\right)$ [16]. Nevertheless, the FE model prediction for the linear part shows stiffer behaviour. That is the second FRP strip experienced early debonding[16]. This made the slab to deviate from the predicted linear behaviour at an early load level of $115 \mathrm{kN}$. Interestingly, the $\mathrm{FE}$ model was able to simulate the debonding progression process; the circled location in figs. 7 (a, b, c and d), and the full debonding after which the slab restores the reference behaviour. Again, the predicted deflection at failure was more conservative than that obtained experimentally. The measured deflections for the prestressed slabs $\left(\mathrm{RS}-\mathrm{F}_{7}\right),\left(\mathrm{RS}-\mathrm{F}_{15}\right)$ and $\left(\mathrm{RS}-\mathrm{F}_{30}\right)$ are about $9 \%, 5 \%$ and $7 \%$ higher than predicted, respectively. Also noticeable is that the deflection at failure of the prestressed slabs is lower as the initial prestressing force increases; implying that the more prestressing force applied the more reduction in slab deformability is achieved.

Table 3 lists the FEM predictions compared to the test results. The failure load predicted by the FE model is within $11 \%$ of the actual failure load. The failure mode predicted is based on checking both the principal compressive strain and steel yielding. For the reference slab $\left(\mathrm{RS}_{0}\right)$, the slab is said to have failed in a flexure punching mode because the flexural steel yields at failure and the yielding of reinforcement spreads over a larger area of the slab. Moreover, the predicted strains are more than two times the yield strain. 
However, for the strengthened slab (RS- $\left.\mathrm{F}_{0}\right)$ the slab is said to have failed in debonding since the composite action is totally lost at the strain localization area around the column. At this corresponding load level; $361.3 \mathrm{kN}$, the interface elements are removed and the slab starts to restore to the reference behaviour, as shown in fig. 7. At this load level, the predicted steel strains have just reached the yield strain and they are confined to a small area locally around the column, see fig. 9a.

For the prestressed slabs, they are said to fail in debonding as the damage parameter at the interface reaches a value of 0.99 of the interface strength, while the principal compressive strain around the column does not exceed the value of 0.0035 . However, for the prestressed slab $\left(\mathrm{RS}-\mathrm{F}_{7}\right)$, the concrete strain, near the column corner at position $\mathrm{SG}_{\mathrm{CH} 2}$, exceeded the ultimate compressive strain at failure. Moreover, the steel strain at position $\mathrm{SG}_{\mathrm{S} 5}$ exceeded the yield strain as well; see fig. 9b. This is due to the prestressing force not being high enough to produce the confinement effect to the concrete in this slab.

For the prestressed slab $\left(\mathrm{RS}-\mathrm{F}_{15}\right)$, neither the concrete nor the steel reached the ultimate compressive strain or the yield strain. At the predicted debonding failure load, the corresponding average concrete strain around the column was within a value of 0.0021 , while the levels of the steel strain were less than 0.0027 . Similar to slab (RS-F 15$)$, both the ultimate compressive concrete strain and yield strain margins were not violated for slab $\left(\mathrm{RS}-\mathrm{F}_{30}\right)$. The average concrete strain around the column was within a value of 0.0018 , and the levels of steel strain were less than 0.0025 . Nonetheless, only strain gauge $\mathrm{SG}_{\mathrm{S}_{5}}$ was close to the yield strain, see fig. 9d. As discussed previously, this may be attributed to slippage of the second FRP strip which allowed the steel reinforcement around the column area to carry more force to compensate the force lost by debonding [16].

It can be seen that slab (RS-F $)$ showed some symptoms of the flexural behaviour. However, these indications could not spread over a large area of the slab and vanished early due to the rapid development of the debonding failure. Such indications would not appear if there was enough confinement from the prestressing force. Thus, the results indicate that increasing the prestressing force increases the ultimate load, but reduces the member ductility. Moreover, the bond characteristics were the main reason for not attaining higher ultimate load in the prestressed slabs.

\subsection{FRP strains and load transfer}

Figure 10 compares the FRP strains predicted by the FE model to the measured strains. some of these load-strain curves, such as that of strain gauge $\mathrm{SGF}_{7}$ for slab $\left(\mathrm{RS}-\mathrm{F}_{0}\right)$, has a horizontal shift at load levels of $305 \mathrm{kN}$, at which the shear crack is expected to develop. The position of this strain gauge is located near the zone where the critical shear crack is developed. Such a crack usually results in a peeling-off of the FRP reinforcement [8]. So, this deviation can then be explained as a consequence of the debonding initiation at the crack mouth, which is characterized by a change in the displacement field at the interface around the crack [9].

As it is well known that the conical shear crack in flat slabs propagates in a mixed mode. When loading is increased, the crack tends to propagate upwards but the crack opening at the bottom is resisted by the FRP plate. A high shear stress level at the 
concrete-adhesive interface is then developed due to the change in the displacement field in the interface layer. As shown in fig. 11, the displacement field after cracking for the interface layer outside the truncated cone suddenly increases, while on the other side of the crack the displacement field decreases. Intuitively, this slip concentration should appear as a high shear stress in the interface layer which results in a crack parallel to the FRP plate at the interface level.

With further loading, the combined opening and shearing of the major crack will result in both horizontal and vertical displacements between the two sides of the crack. So, the FRP plate is subjected to a combined pulling and peeling effect. In such a case, the peeling force generates tensile stresses acting perpendicular to the interface, as shown in fig. 11. These stresses make it easier for initial debonding to occur in the area outside the truncated cone. Moreover, the opening displacement (in the direction normal to the interface) along the debonded part of the interface reduces the interlocking effect and accelerates debonding. Correspondingly, a strain gauge near an area such as $\mathrm{SG}_{\mathrm{F} 7}$ will experience high strain levels after debonding, as shown in fig. 10. However, such displacements will increase the interlocking effect on the other side of the crack. So, any strain gauge located inside the truncated cone, such as a strain gauge $\mathrm{SG}_{\mathrm{F} 5}$, will have a mild increase rate after debonding, as shown in fig. 10.

Also shown in fig. 10b is the predicted strain distributions along a representative length of the bonded FRP plate, for slab $\left(\mathrm{RS}-\mathrm{F}_{15}\right)$, compared to the measured strains at different load levels. The circled zone in the figure indicates a change in the slope of the curve at the end of the overlapped FRP location. That is the FRP-concrete interfacial behaviour is directly related to the strain of the FRP plate. Intuitively, such change in the slope is a result of lower strains at the FRP overlapped locations. This reduction in the strain level at the overlapping is due to the effect of the lateral Poisson's ratio $v_{21}$, which transfers the effect of the prestressing force in the second direction into a compressive force in the first direction and vice versa. By comparing the predicted strains to the measured strains, it can be noticed that the numerical results are in good agreement with the measured strains over most of the loading history. Moreover, the model was able to simulate the overlapping phenomenon before failure.

\subsection{FRP-concrete interfacial behaviour}

The FE model was used to predict the FRP-concrete interfacial behaviour. Figure 12 shows the interfacial shear stress distribution for the non-prestressed slab (RS-F $\mathrm{F}_{0}$ at the plate centreline at different load levels. The behaviour can be easily simplified as a half sine-wave travelling from the slab centre towards the end of the FRP plate. The crest denotes the location of the maximum shear stress which begins near the slab centre where the maximum radial moment occurs. The change in the slope of the interfacial shear stress distribution at the overlapping area, as shown in the circled area on the figure, is a well-known phenomenon. It indicates a decrease in the slope rate due to the overlapping of the FRP plates which results in lower slip values. The interfacial shear stress values then decreases gradually towards the plate end.

After cracking, the interfacial shear stress; near the maximum radial moment area, increases significantly, see curve $(149.8 \mathrm{kN})$ in fig. 12a. At this stage of loading, the stress concentration starts to appear near the plate end as well, but with less concentration due to the presence of the anchor plates. The shear stress distribution still 
has a gradual descending trend towards the plate end, but with some fluctuation. This fluctuation is attributed to the unsymmetrical position of the FRP plate around the column, by which uneven distribution of the stresses across the plate width occurs. As a result, the outer edges of the FRP plate starts to debond before the inner edges. In this case, some stress concentration appears at discrete adjacent locations on the centre line of the plate, resulting in such behaviour. This can be easily identified from the crack pattern of the slab which is discussed in the next section.

As the load is further increased $(270.5 \mathrm{kN})$, the shear stress reaches a peak value after which the stress values descend progressively, as shown in fig. 12b. At the overlapping of the FRP plate, the interfacial shear stress progresses negatively, allowing the damage to occur in subsequent locations. After yielding of the tension reinforcement, the interfacial shear stress keeps increasing with the increase of load. The full debonding of the FRP plate occurs at load level of $361.3 \mathrm{kN}$ at the overlapping position when the interfacial shear stress reaches 1.6 MPa. It may seem that this value of shear stress is too low. However, a value much lower such as $0.2 \mathrm{MPa}$ has been reported in the literature [24], as the bond strength is highly dependent on the plate geometry and stiffness [25].

Figure 13 shows the numerical predictions of the interfacial shear stress distribution for the prestressed slab $\left(\mathrm{RS}-\mathrm{F}_{15}\right)$ at different load levels. Its behaviour, to some extent, is similar to the non-prestressed slab $\left(\mathrm{RS}-\mathrm{F}_{0}\right)$. However, at the early stages of loading before cracking, the shear stress levels along the plate length were high compared to the non-prestressed slab $\left(\mathrm{RS}-\mathrm{F}_{0}\right)$, especially near the anchor plate. It seems that the high prestressing force in the FRP plate helps more stress concentration at the plate end. The stress concentration near the plate end is a well-known phenomenon, which has been studied by many researchers before[26-28]. It is caused by a sudden change in the strengthened section due to the termination of the FRP plate. In the same vein, the interfacial shear stress near the maximum radial moment area increases significantly after cracking due to the localized concrete cracking. A change in the slope of the interfacial shear stress distribution at the overlapping area is developed, as shown in the circled area on the figure. The shear stress near the anchor plate has got a large increase as well, so the shear stress level at the plate end is still higher than that near the slab centre, as shown by the second lowest curve $(171.4 \mathrm{kN})$ in fig. $13 a$.

It is noticed that the fluctuation of the shear stress profile is less severe than the stress profile of slab $\left(\mathrm{RS}-\mathrm{F}_{0}\right)$. That is the high prestressing force was able to distribute the stresses across the plate width. As a result, the time difference between the debonding of the nodes across the FRP plate is considerably diminished. This can be easily identified from the crack pattern of the slab, as will be shown later.

When the load is further increased, the shear stress at the slab centre reached the peak value 1.6 MPa then decreased gradually, as shown from fig. 13b. However, the interfacial shear stress at the overlapping position did not progress negatively, but still had lower stress levels than the surrounding points. This could be attributed to the high prestressing force which was able to reduce the rate of slip changes at the plate overlapping. At the later stages of loading (load level $233.9 \mathrm{kN}$ ) the interfacial shear stress just after the overlapping position reaches the bonding strength, while the shear stress near the plate end is still lower than the bond strength (0.92 MPa). Most interestingly, the debonding progression of the prestressed slabs was very fast compared 
to the non-prestressed slab $\left(\mathrm{RS}-\mathrm{F}_{0}\right)$. One can easily identify that the debonding of 525 $\mathrm{mm}$ of the FRP plate occurred in the last ten kNs before failure.

\subsection{Crack pattern}

Figure 14 shows the numerical prediction of crack pattern of the bottom surface of slabs $\left(\mathrm{RS}_{0}\right),\left(\mathrm{RS}-\mathrm{F}_{0}\right),\left(\mathrm{RS}-\mathrm{F}_{15}\right),\left(\mathrm{RS}-\mathrm{F}_{30}\right)$ at the predicted failure loads of 226.8, 372.7, 239.9, $305.7 \mathrm{kN}$, respectively. The figure shows the direction of the tensile equivalent plastic strain, $\widetilde{\varepsilon}_{t}^{p l}$, its vector is normal to the crack plane. So, to determine a crack path an imaginary line tracing the points of maximum tensile plastic strain might be considered.

For the non-prestressed slab $\left(\mathrm{RS}-\mathrm{F}_{0}\right)$, the crack strains started to occur tangentially at the area of the maximum bending moment near the column then spread radial towards the slab edges as the load increased. A noticeable large crack strain occurred at the inner and outer edges of the FRP plates, while relatively small strains occurred at the area just beneath the plates where they are bonded to the concrete substrate; see fig. A-2 in the appendix. The figure also shows a good prediction for the position of the yield lines and their progress; extending between the slab centre and near the slab corner. They are comparable to those experienced in the experimental programme; see the picture in fig. $14 \mathrm{~b}[16]$.

Also by comparing the cracking patterns and their corresponding loads of the nonprestressed slab $\left(R S-F_{0}\right)$ and the reference slab $\left(R_{0}\right)$, one can see that the nonprestressed slab $\left(\mathrm{RS}-\mathrm{F}_{0}\right)$ achieved a noticeable cracking resistance by bonding the FRP plates, as the reinforcement ratio is increased.

The cracking of the prestressed slabs followed a different behaviour from the nonprestressed slab $\left(\mathrm{RS}-\mathrm{F}_{0}\right)$ and the reference slab $\left(\mathrm{RS}_{0}\right)$. Firstly, the crack strains started to occur tangentially at the area of the maximum bending moment near the column then spread radial towards the slab edges as the load increased. Noticeable large crack strains started to occur at the outer edges of the FRP plates, while relatively small strains occurred at the area just beneath the plates, where they are bonded to the concrete substrate. This was accompanied with more stress concentration at the plate end. Within a few kNs later, cracks started to appear along the inner edges of the FRP plate and extended up to the slab edges. As the load was further increased, another crack path parallel to the inner edge of the FRP plate was noticed. This crack line extended to the slab edges, to the points which determine the length of the slab edge that does not contact the support. This crack pattern was then kept until failure occurred; see fig. A-3 in the appendix. It should be mentioned that, for all prestressed slabs, the development of cracking passed nearly the same stages, but at different load levels for each slab. This was depending on the amount of the prestressing force used. Consequently, by comparing the loads corresponding to the stages of crack development between the prestressed slabs, it could be concluded that the higher the prestressing force used the more crack resisting capability is obtained. Also, the initial cracking area and intensity is reduced as the prestressing force is increased. Thus, the crack resisting capability of the prestressed slabs has remarkably increased.

\subsection{Crack opening displacement}


Large deflections and excessive cracking significantly influences the serviceability of structural members. It has been demonstrated before that bonding FRP plates to the tension surface of concrete slabs does not only reduce the crack widths, but also shifts the shear crack positions away from the loading region This was confirmed by the reading of the pots positioned at the notched crack, which gave zero measurements [16]. This can be further supported by drawing the load versus crack mouth opening displacement (CMOD) obtained at the strain localization area within a distance of $1.5 \mathrm{~d}$ from the column face, based on FEA. In this case, the CMOD can be assumed equal to the tensile equivalent plastic strain, $\widetilde{\varepsilon}_{t}^{p l}$, at the tension face of the slab multiplied by the characteristic length of the FE mesh. As shown in fig. 15, there exists clear evidence that the application of the FRP reinforcement; in slab $\left(\mathrm{RS}-\mathrm{F}_{0}\right)$, reduced the crack opening displacement. For example, at a load level of $250 \mathrm{kN}$ the percentage reduction in the CMOD is about $40 \%$ of the reference slab. That implies an enhanced serviceability of the strengthened member. It is clear that the application of the FRP reinforcement reduced the crack opening displacement. Moreover, increasing the prestressing force resulted in more reduction in the crack opening which implies more enhancement in the serviceability of the strengthened member. This can be easily identified by comparing the crack opening at a certain load level. For example, at load level $200 \mathrm{kN}$ the corresponding opening displacement for slabs $\left(\mathrm{RS}_{0}\right),\left(\mathrm{RS}-\mathrm{F}_{15}\right)$ and $\left(\mathrm{RS}-\mathrm{F}_{30}\right)$ are $0.26,0.18$ and $0.005 \mathrm{~mm}$, respectively, which clearly reflects the effect of changing the prestressing force. However, by comparing the opening displacement in the early stages of loading such as $90 \mathrm{kN}$, which is usually the common service load for slabs with such design, no significant difference could be identified for the prestressing effect in reducing the CMODs, compared to the non-prestressed slab (RS- $\left.\mathrm{F}_{0}\right)$.

\section{Conclusion}

This study has investigated the punching shear behaviour of RC column-slab connections with low reinforcement ratios, and strengthened with externally bonded FRP reinforcement. The available test data of five full-scale RC slabs strengthened with non-prestressed or prestressed FRP plates were analysed by using three-dimensional FE analysis. The following conclusions can be drawn from the present study:

The FE analysis; adopting the mixed mode behaviour at the interface, enables detailed investigation of the interfacial behaviour, and is able to capture the onset of debonding and macro-debonding which is very difficult to identify in the physical tests. The developed model gave a conservative prediction of the ultimate load within only $5 \%$ of the actual failure load. Also, it provided an accurate prediction of the crack patterns which agree to the previous experimental results.

The application of the FRP reinforcement increases the punching capacity of the strengthened slabs compared to the reference slab $\left(\mathrm{RS}_{0}\right)$, but simultaneously decreases the deformation capacity, which is translated into smaller steel strains at failure. The application of prestressed FRP plates result in a large reduction in the deformation capacity, provided that the full composite action is maintained.

Applying prestressed FRP plates to the tension surface of slabs, enhances the serviceability in terms of stiffer load-deflection behaviour and smaller crack mouth opening displacements (CMODs), compared to the non-prestressed applications. This is attributed to the confinement effect of the prestressing forces. 
Applying FRP plates with limited width, in unsymmetrical position around the column area, results in uneven distribution of the stresses across the plate width. This triggers the debonding process at the outer edges of the FRP plates, near the maximum radial moment area, before the inner edges. That is some stress concentration appears at these locations.

After debonding initiation, the rate of strain increase in the FRP plate for the prestressed slabs is higher than that of the non-prestressed slabs. This higher rate is attributed to the sudden transfer of forces to the FRP plates at the onset of debonding. The magnitude of the increase in strain is highest at debonding cracks near the slab centre, and gradually reduces away towards the plate end.

\section{Acknowledgement.}

The authors acknowledge the financial support of Egypt High Ministry of Education. Weber Building solutions have provided The FRP materials. Thanks are extended to the technical staff at the School of Mechanical, Aerospace and Civil Engineering, University of Manchester for their assistance during various stages of the project.

\section{Appendix A}

\section{References}

[1]. Binici, B. and O. Bayrak, Use of fiber-reinforced polymers in slab-column connection upgrades. ACI Structural Journal, 2005. 102(1): p. 93-102.

[2]. Koppitz, R., A. Kenel, and T. Keller, Punching shear strengthening of flat slabs using prestressed carbon fiber-reinforced polymer straps. Engineering Structures, 2014. 76: p. 283-294.

[3]. Ebead, U. and H. Marzouk, Fiber-reinforced polymer strengthening of two-way slabs. ACI Structural Journal, 2004. 101(5): p. 650-659.

[4]. El-Salakawy, E., K. Soudki, and M.A. Polak, Punching shear behavior of flat slabs strengthened with fiber reinforced polymer laminates. Journal of Composites for Construction, 2004. 8(5): p. 384-392.

[5]. Sharaf, M.H., K.A. Soudki, and M. Van Dusen, CFRP strengthening for punching shear of interior slab-column connections. Journal of Composites for Construction, 2006. 10(5): p. 410-418.

[6]. Moe, j., Shearing strength of reinforced concrete slabs and footings under concentrated loads, in Development Department Bulletin No. D47. 1961, Portland Cement Association: Skokie. p. 130.

[7]. Triantafillou, T.C. and N. Plevris, Strengthening of RC beams with epoxybonded fiber-composite materials Materials and structures, 1992. 25: p. 201211.

[8]. Pan, J. and C.K.Y. Leung, Debonding along the FRP-concrete interface under combined pulling/peeling effects. Engineering Fracture Mechanics, 2007. 74(12): p. 132-150.

[9]. Lu, X.Z., et al., Intermediate crack debondong in FRP-strengthened RC beams: FE analysis and strength model. Journal of Composites for Construction, 2007. 11(2): p. 161-174.

[10]. Seim, W., et al., External FRP poststrengthening of scaled concrete slabs. Journal of Composites for Construction, 2001. 5(2): p. 67-75. 
[11]. ACI, Guide for the design and construction of externally bonded FRP systems for strengthening concrete structures (ACI 440.2R-08). 2008, American Concrete Institute. p. 45.

[12]. CSA, Design and construction of building components with fibre reinforced polymers. 2002, Canadian Standards Association International (CSA): Toronto.

[13]. ISE, Interim guidance on the design of reinforced concrete structures using fibre composite reinforcement. 1999, Institution of Structural Engineers (ISE): London.

[14]. Hollaway, L. and M.B. Leeming, Strengthening of reinforced concrete structures : using externally-bonded FRP composites in structural and civil engineering. 2003, Norwich, NY: Knovel.

[15]. Lu, X.Z., et al., Meso-scale finite element model for FRP sheets-plates bonded to concrete. Engineering Structures, 2005. 27: p. 564-575.

[16]. Abdullah, A.M., Analysis of Repaired/Strengthened R.C. Structures Using Composite Materials: Punching Shear, in School of MACE. 2010, Manchester university: Manchester.

[17]. Eurocode 2; Design of concrete structures: BS EN 1992-1-1and BS EN 1992-12. 2004.

[18]. ABAQUS Theory Manual, User Manual and Example Manual, Version 6.8, Providence, RI. 2009.

[19]. Lubliner, J., et al., A plastic-damage model for concrete. International Journal of Solids and Structures, 1989. 25(3): p. 299-326.

[20]. Lee, J. and G.L. Fenves, Plastic-damage model for cyclic loading of concrete structures. Journal of Engineering Mechanics, 1998. 124(8): p. 892-900.

[21]. Scanlon, A. and D.W. Murray, Time-dependent reinforced concrete slab deflection. Journal of Structural Division, 1974. 100: p. 1911-1924.

[22]. Kollár, L.P. and G.S. Springer, Mechanics of composite structures. 2003.

[23]. Lu, X.Z., et al., Bond-slip models for FRP sheets/plates bonded to concrete. Engineering Structures, 2005. 27(6): p. 920-937.

[24]. Niu, H., V.M. Karbhari, and Z. Wu, Diagonal macro-crack induced debonding mechanisms in FRP rehabilitated concrete composites Part B:Engineering, 2006. 37: p. 627-641.

[25]. Niu, H. and Z. Wu, Numerical analysis of debonding mechanisms in FRPstrengthened RC beams. Computer-Aided Civil and Infrastructure Engineering, 2005. 20: p. 354-368.

[26]. Kim, Y.J., R.G. Wight, and M.F. Green, Flexural strengthening of RC beams with prestressed CFRP sheets: Developemet of nonmetallic anchor systems. Journal of composites for construction, 2008. 12(1).

[27]. Malek, A.M., H. Saadatmanesh, and M.R. Ehsani, Prediction of failure load of $R C$ beams strengthened with FRP plates due stress concentration at the plate end. ACI Structural Journal, 1998. 95(1): p. 142-152.

[28]. Triantafillou, T.C., N. Deskovic, and M. Deuring, Strengthening of concrete structures with prestressed fiber reinforced plastic sheets. ACI Structural Journal, 1992. 89(3): p. 235-244. 
Table 1: Details of test specimens.

\begin{tabular}{cccc}
\hline Specimen & $\begin{array}{c}\text { Prestressing } \\
\text { Ratio \% }\end{array}$ & $\begin{array}{c}\text { Applied load } \\
(\mathrm{kN})\end{array}$ & $\begin{array}{c}\text { Applied FRP } \\
\text { strain \%o }\end{array}$ \\
\hline $\mathrm{RS}_{0}$ & ------ & ------ & ----- \\
$\mathrm{RS} \mathrm{F}_{0}$ & 0 & 0 & 0 \\
$\mathrm{RS}-\mathrm{F}_{7}$ & 7.5 & 43 & 0.19 \\
$\mathrm{RS}-\mathrm{F}_{15}$ & 15 & 45 & 0.28 \\
$\mathrm{RS}-\mathrm{F}_{30}$ & 30 & 93 & 0.49 \\
\hline
\end{tabular}

Table 2: Summary of material properties for FRP composites.

\begin{tabular}{ccccc}
\hline $\begin{array}{c}\text { Elastic Modulus } \\
(\mathrm{MPa})\end{array}$ & $\begin{array}{c}\text { Major } \\
\text { Poisson's } \\
\text { ratio }\end{array}$ & $\begin{array}{c}\text { Shear } \\
\text { modulus } \\
(\mathrm{MPa})\end{array}$ & $\begin{array}{c}\text { Tensile/shear } \\
\text { strength } \\
(\mathrm{MPa})\end{array}$ & $\begin{array}{c}\text { Thickness of } \\
\text { plate }(\mathrm{mm})\end{array}$ \\
\hline$E_{x}=165000$ & $v_{x y}=0.29^{(2)}$ & $G_{x y}=5127.5^{(3)}$ & $X_{t}=2970$ & \\
$E_{y}=14050^{(1)}$ & $v_{x z}=0.29$ & $G_{x z}=5127.5$ & $Y_{t}=69^{(5)}$ & 1.2 \\
$E_{z}=14050$ & $v_{y z}=0.6^{(5)}$ & $G_{y z}=4390.6^{(4)}$ & $S=87^{(5)}$ & \\
\hline
\end{tabular}

$\begin{array}{ll}\text { (1) } \frac{1}{E_{y}}=\frac{V_{f}}{E_{f x}}+\frac{V_{m}}{E_{m}} & \text { (2) } v_{x y}=V_{f} v_{f x y}+V_{m} v_{m}\end{array}$

$\begin{array}{ll}\text { (3) } G_{x y}=\left(\frac{V_{f}}{G_{f x y}}+\frac{V_{m}}{G_{m}}\right)^{-1} & \text { (4) } G_{y z}=\frac{E_{y}}{2\left(1+v_{y z}\right)}\end{array}$

(5) Other properties of the constitutive materials such as $v_{y z}, E_{f x y}, v_{m}$ and $G_{m}$ are assumed according to typical material properties published in Kollár and Springer [22]. The volume fraction is provided by the manufacturer; $V_{f}=70 \%$.

Table 3: Experimental and FEM predictions of ultimate load and failure mode.

\begin{tabular}{|c|c|c|c|c|c|}
\hline \multirow[b]{2}{*}{ Specimen } & \multicolumn{2}{|c|}{ Test } & \multicolumn{2}{|c|}{ FEM } & \multirow{2}{*}{$\begin{array}{l}\text { Ultimate } \\
\text { Load ratio } \\
\text { FEM/Test }\end{array}$} \\
\hline & $\begin{array}{l}\text { Ultimate } \\
\text { load }(\mathrm{kN})\end{array}$ & $\begin{array}{l}\text { Failure } \\
\text { mode }\end{array}$ & $\begin{array}{l}\text { Ultimate } \\
\text { load }(\mathrm{kN})\end{array}$ & $\begin{array}{l}\text { Failure } \\
\text { mode }\end{array}$ & \\
\hline $\mathrm{RS}_{0}$ & 284 & $\begin{array}{l}\text { Flexural } \\
\text { punching }\end{array}$ & 253.7 & $\begin{array}{l}\text { Flexural } \\
\text { punching }\end{array}$ & 0.89 \\
\hline $\mathrm{RS}-\mathrm{F}_{0}$ & 405.2 & Punching & 361.3 & Debonding & 0.89 \\
\hline $\mathrm{RS}-\mathrm{F}_{7}$ & 220 & Debonding & 215.7 & Debonding & 0.98 \\
\hline $\mathrm{RS}-\mathrm{F}_{15}$ & 240 & Debonding & 236.5 & Debonding & 0.99 \\
\hline $\mathrm{RS}-\mathrm{F}_{30}$ & 307 & Debonding & 292.4 & Debonding & 0.95 \\
\hline
\end{tabular}



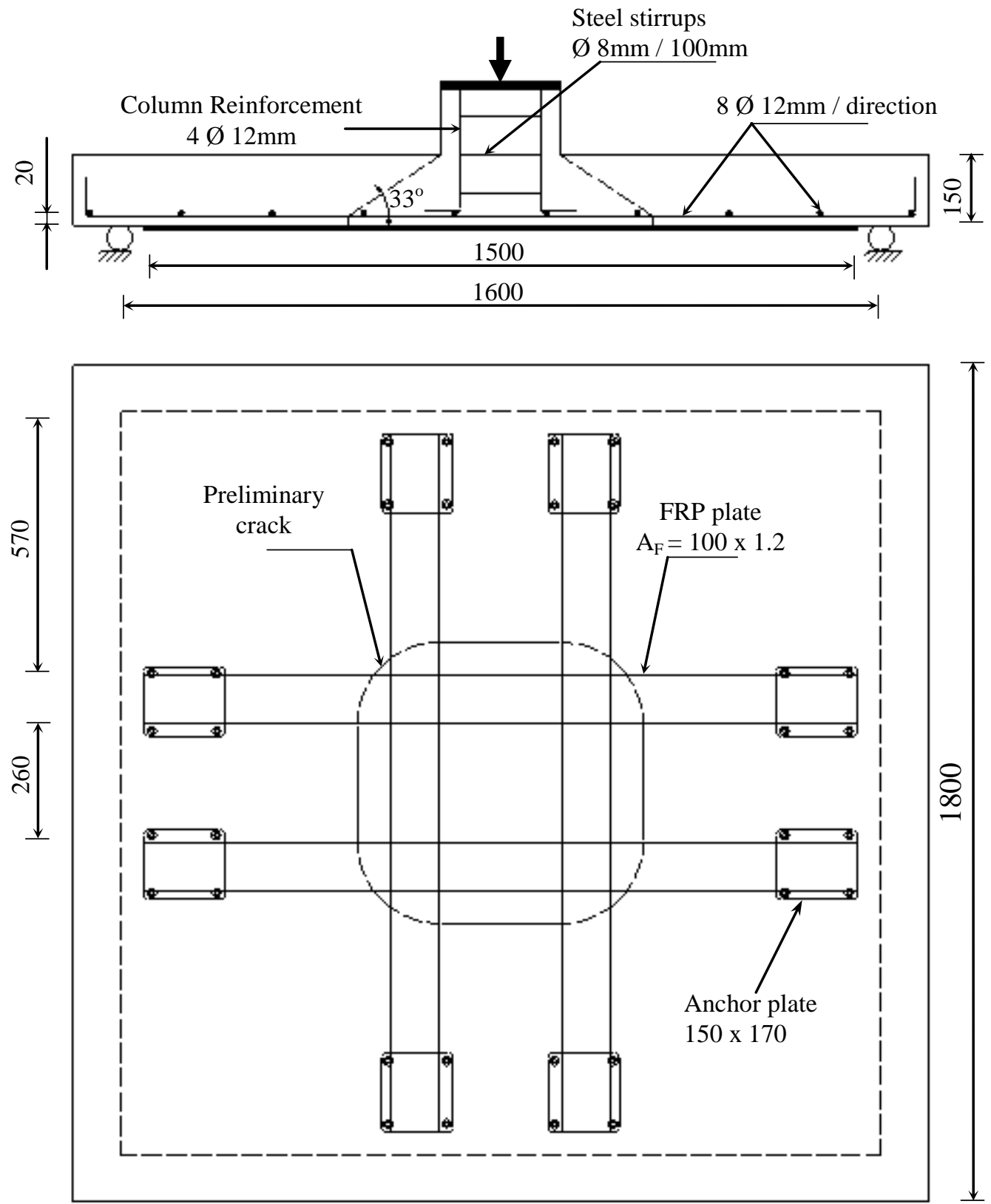

Fig. 1. Geometric and reinforcement details of test slabs. 


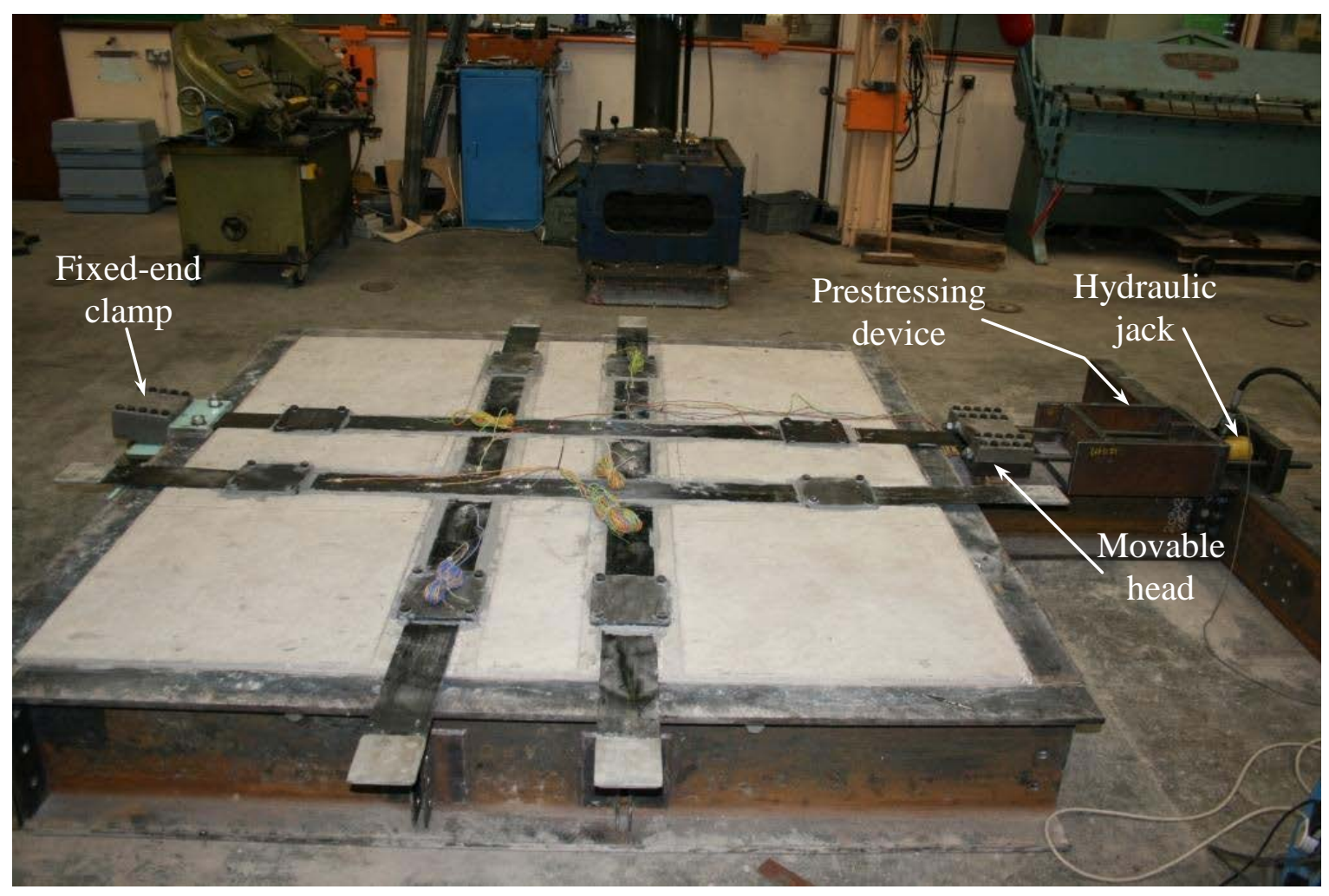

Fig. 2. Layout of prestressing device.

(a)

Linear

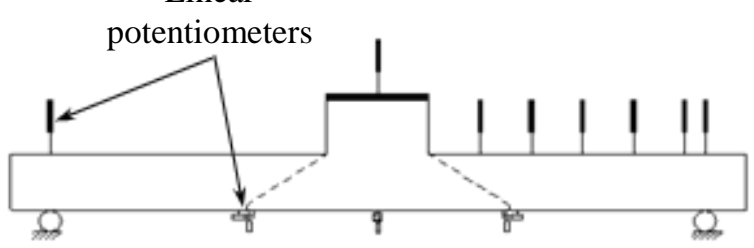

(c)

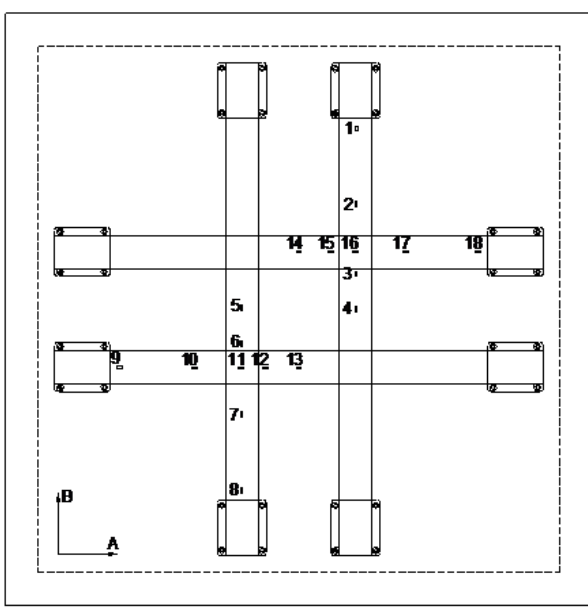

(b)

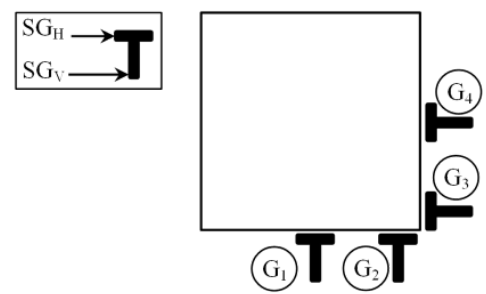

(d)

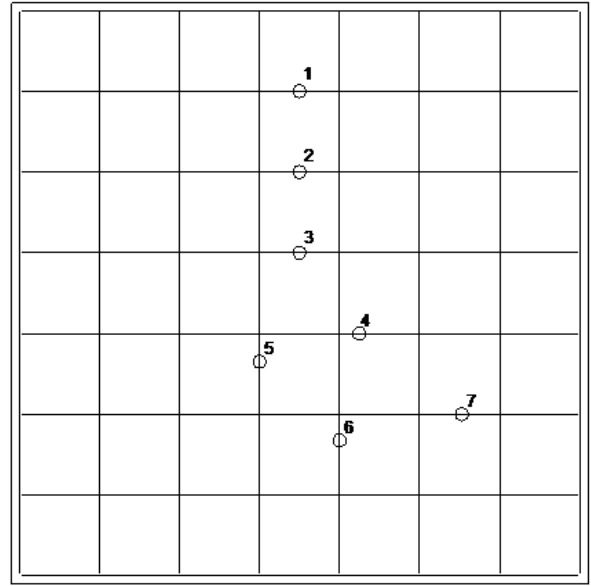

Fig. 3. Test setup: (a) Front view of test setup and Pots positions, (b) Concrete strain gauges around column, (c) FRP strain gauges, (d) steel strain gauges. 


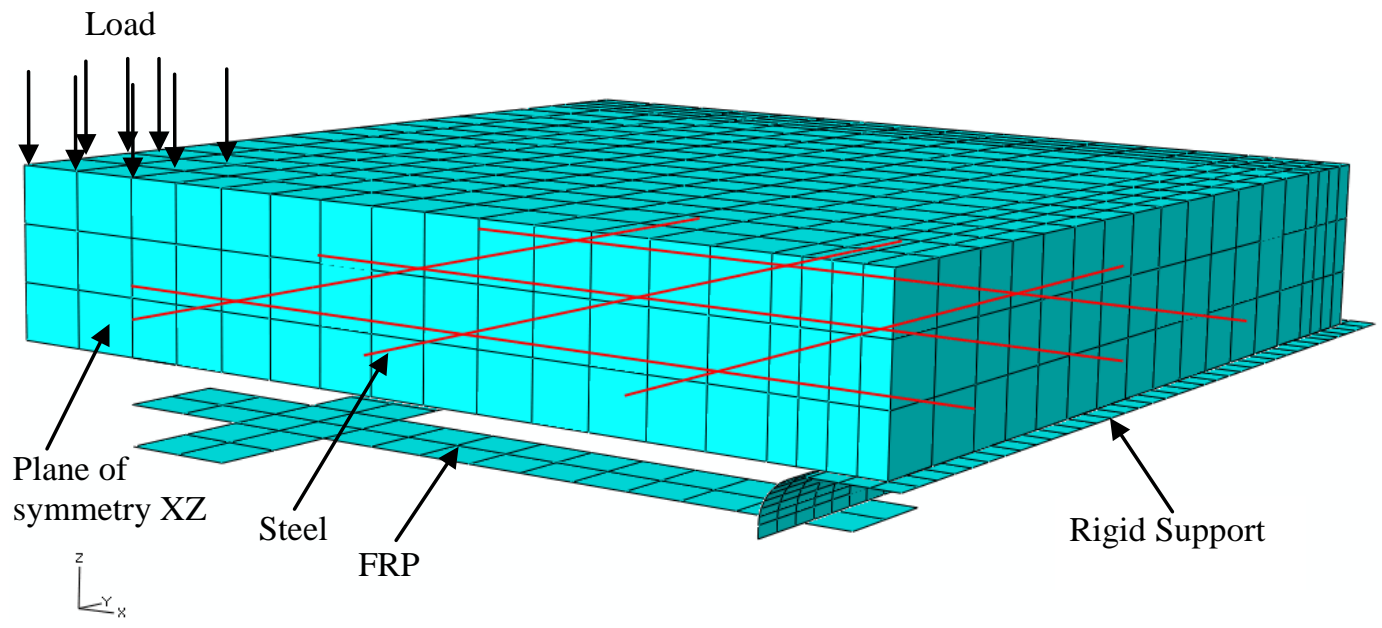

Fig. 4. Slab model; FRP reinforcement has been shifted down for clarity purposes. 


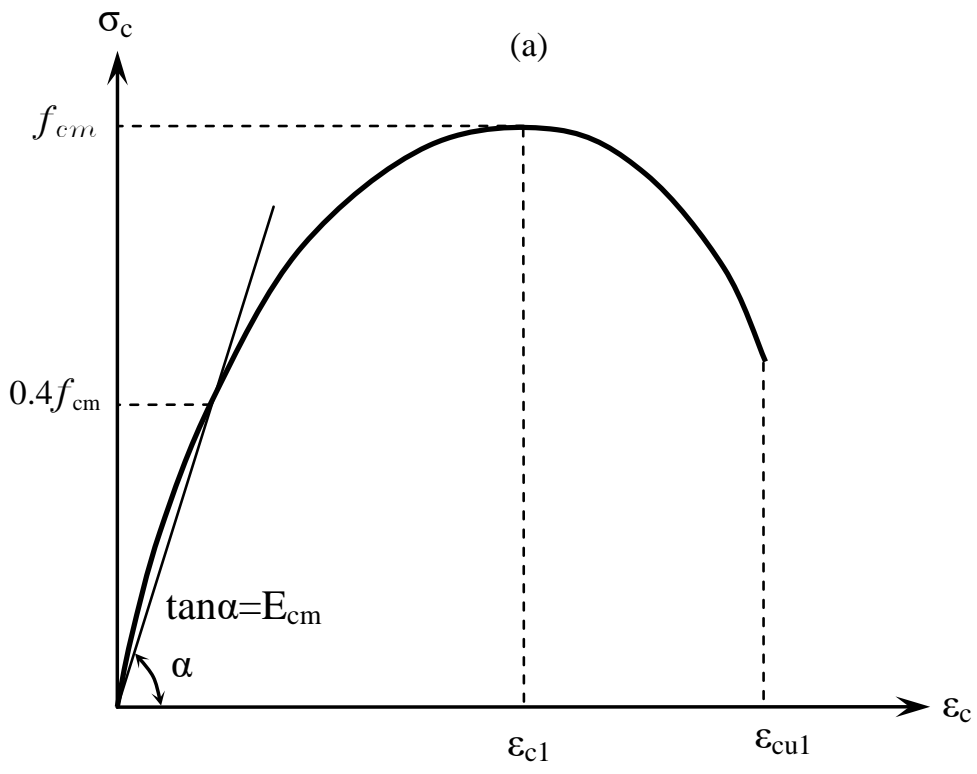

(b)

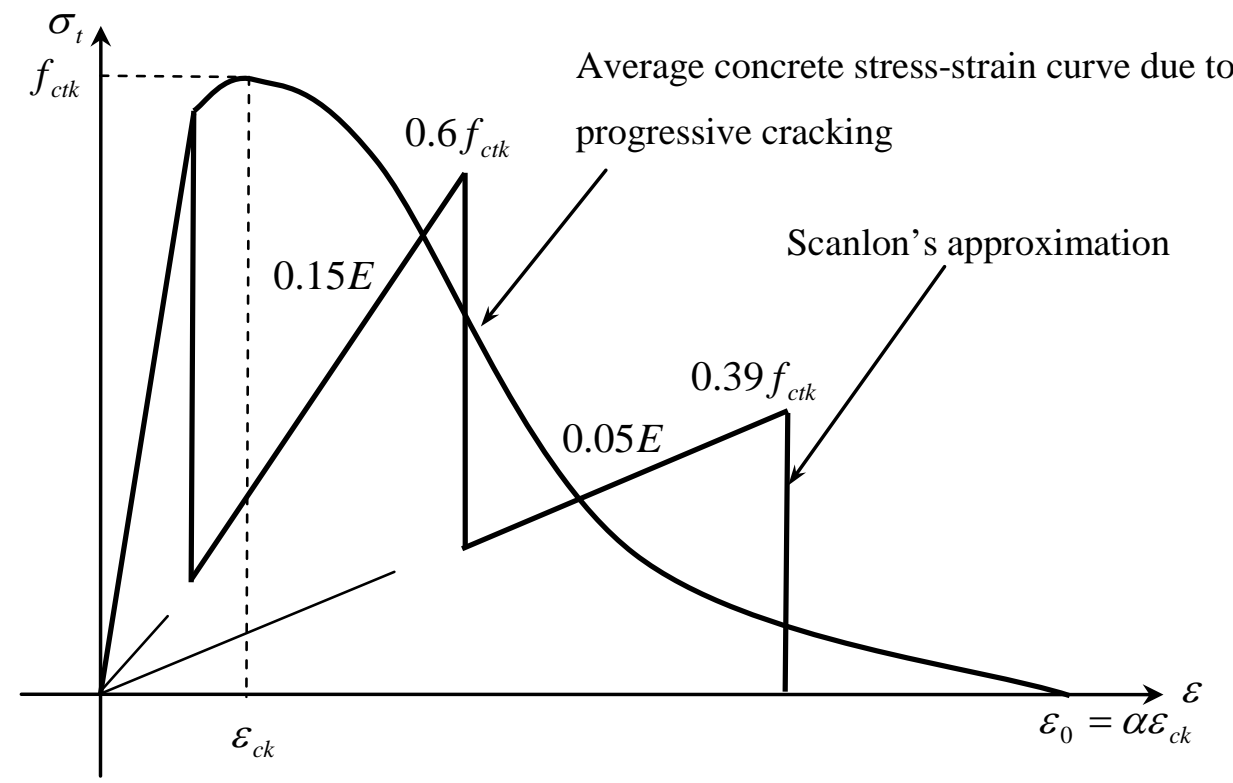

Fig. 5. Uniaxial stress-strain relationships of concrete: (a) concrete in tension, (b) concrete in compression. 


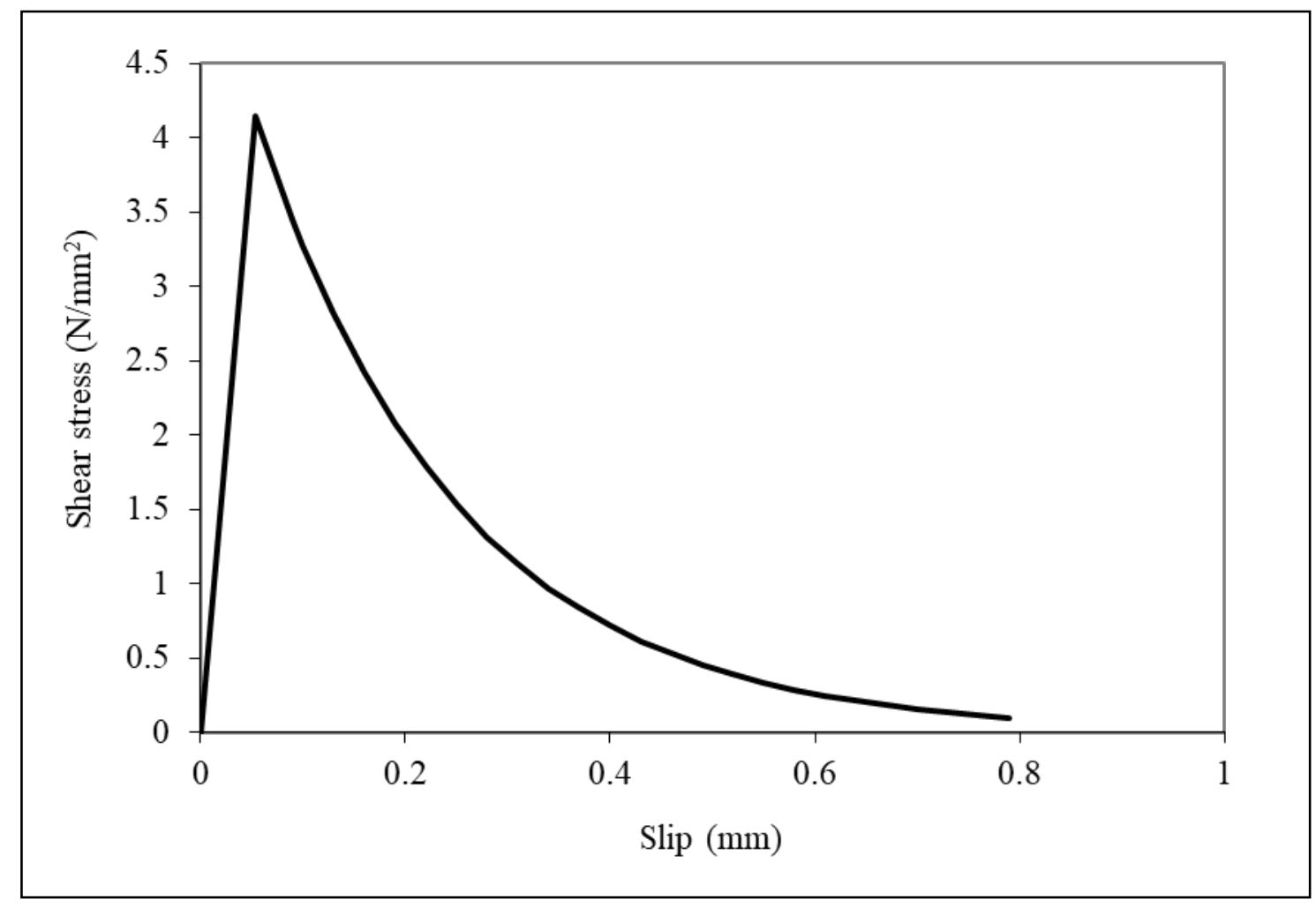

Fig. 6. FRP-concrete interfacial stress-slip model. 


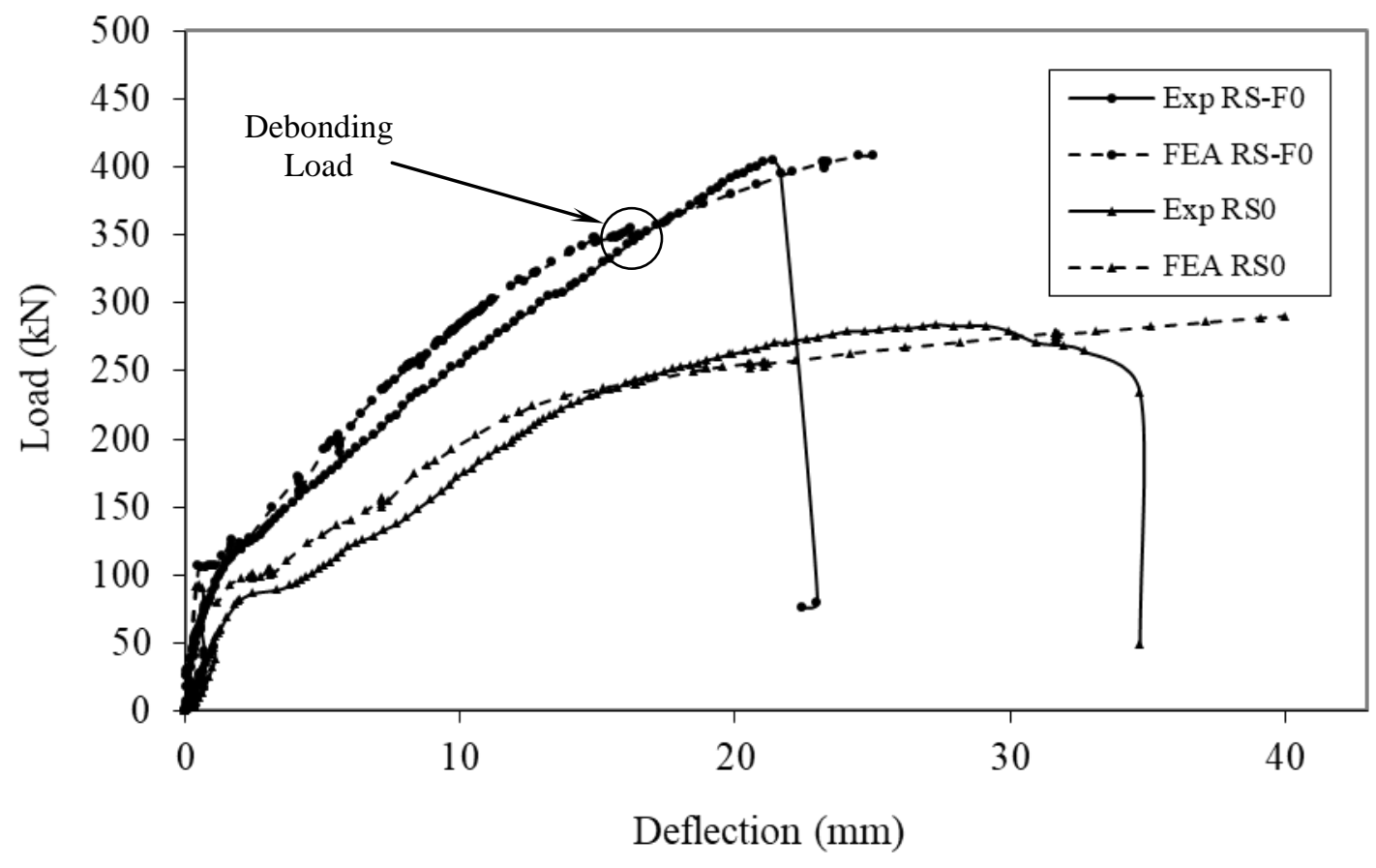

(a)

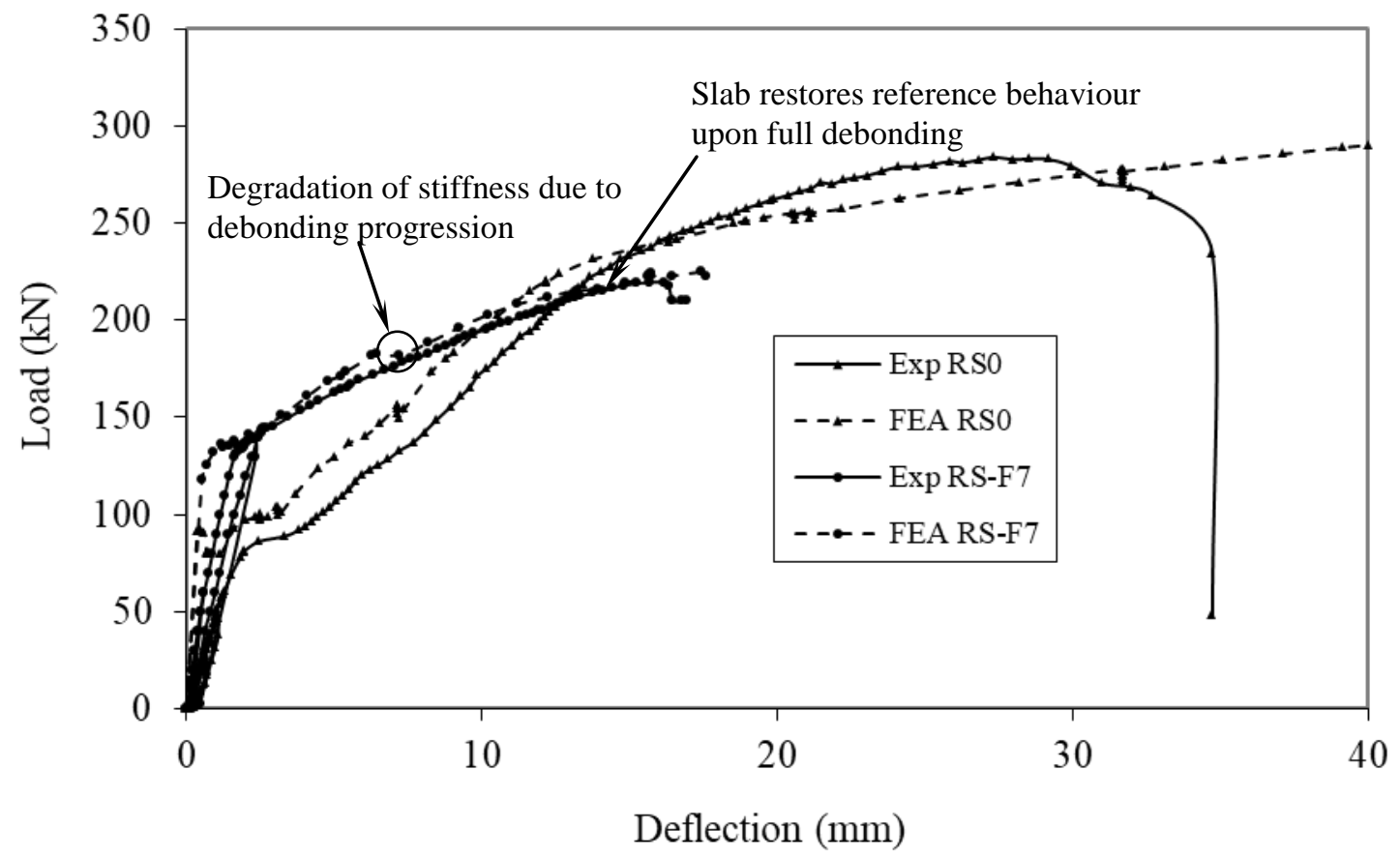

(b) 


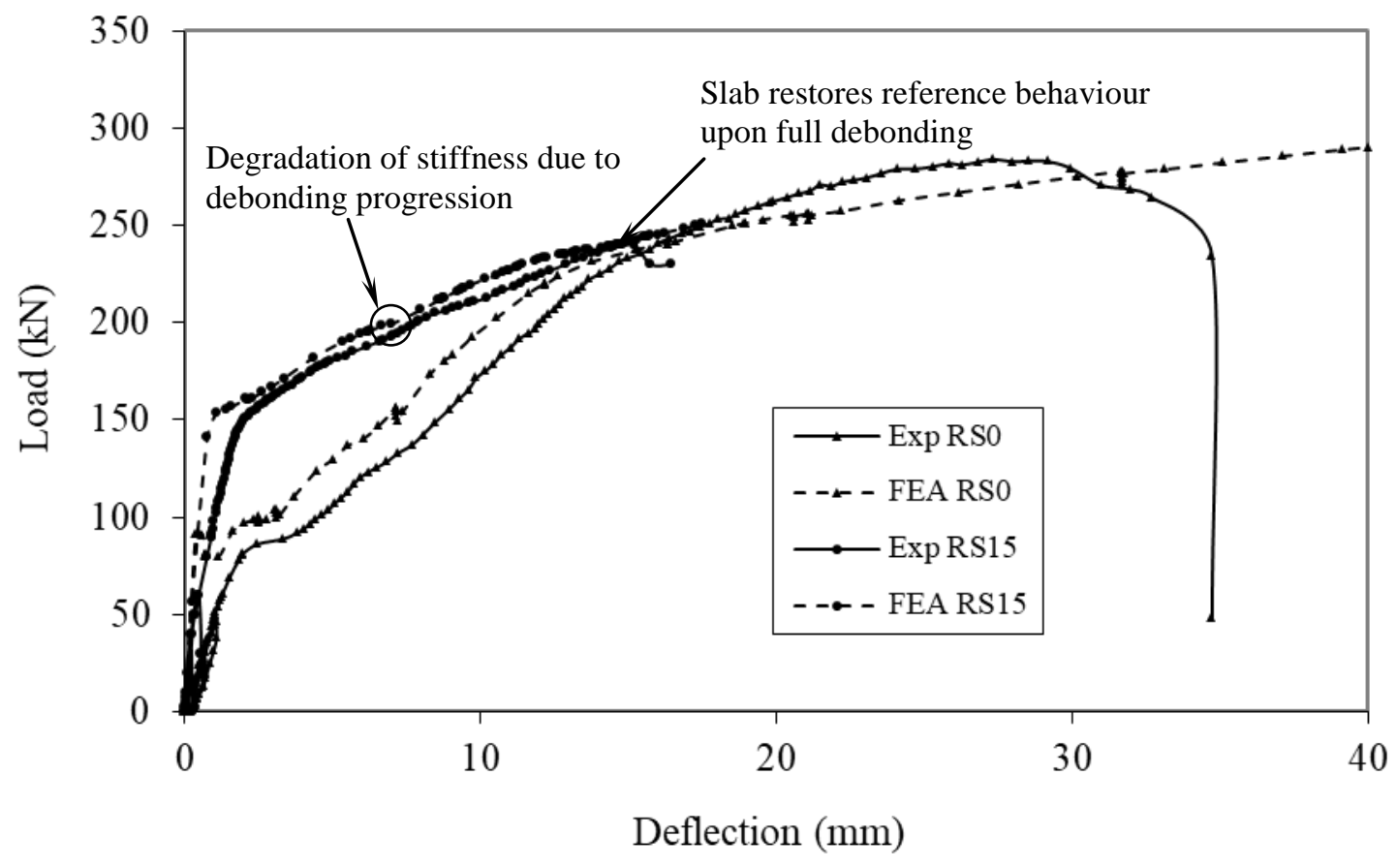

(c)

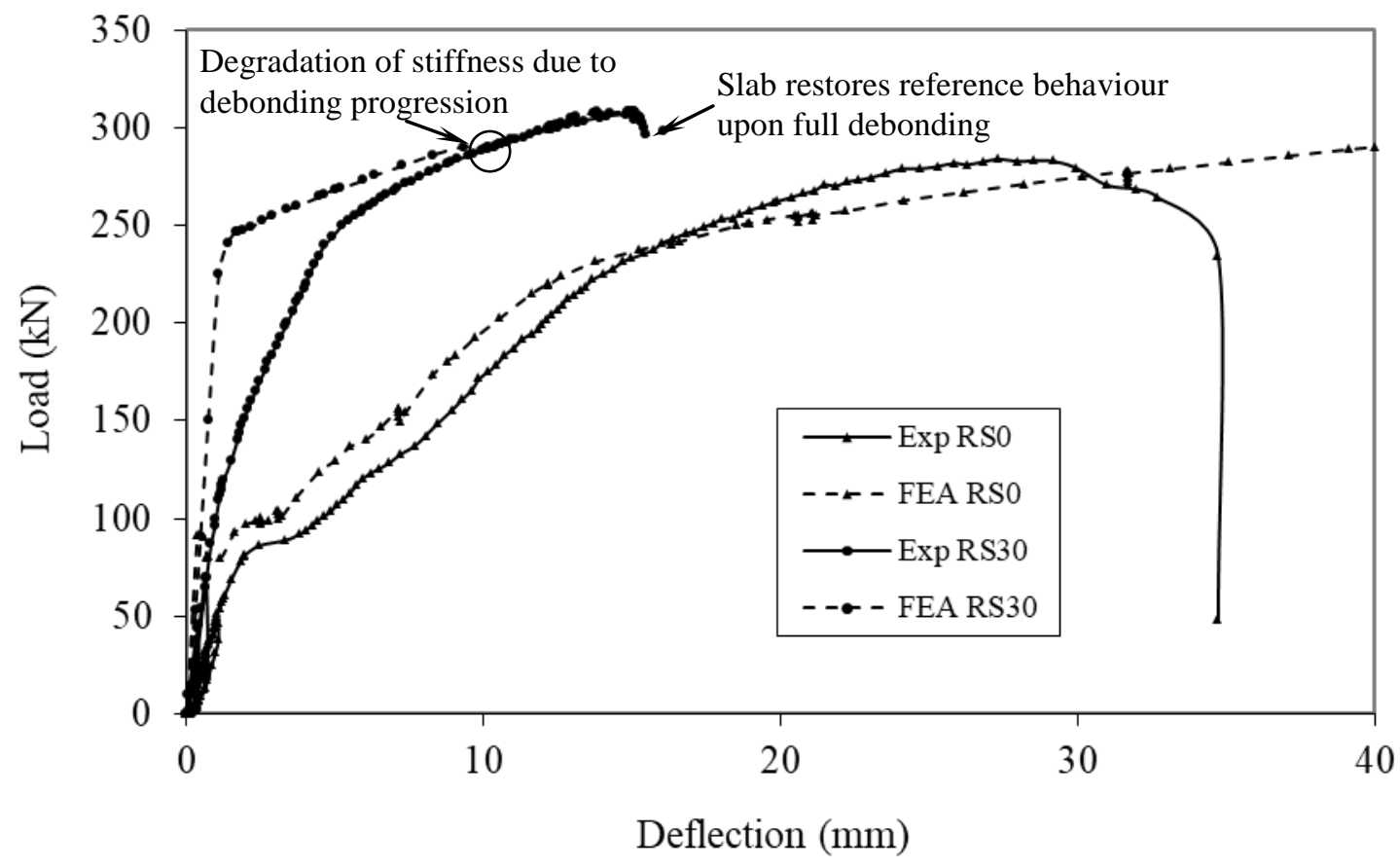

(d)

Fig. 7. Comparison between experimental and model prediction for tested slabs: (a) slab RS-F ; (B) slab RS-F $F_{7}$ (c) slab RS-F 15 and (d) slab RS- $F_{30}$. 


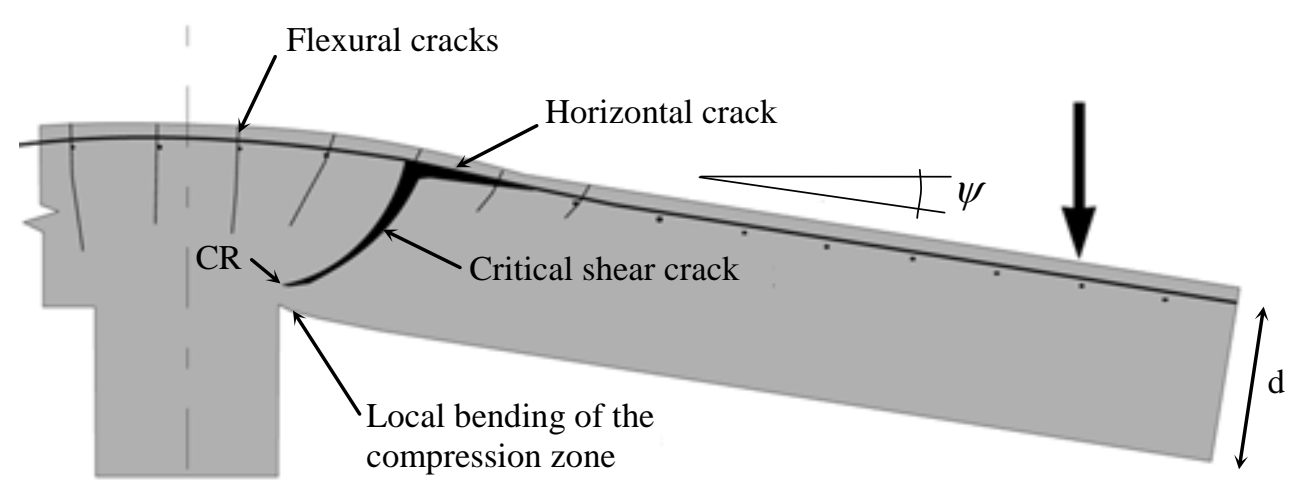

$\mathrm{V} \uparrow$

(a)

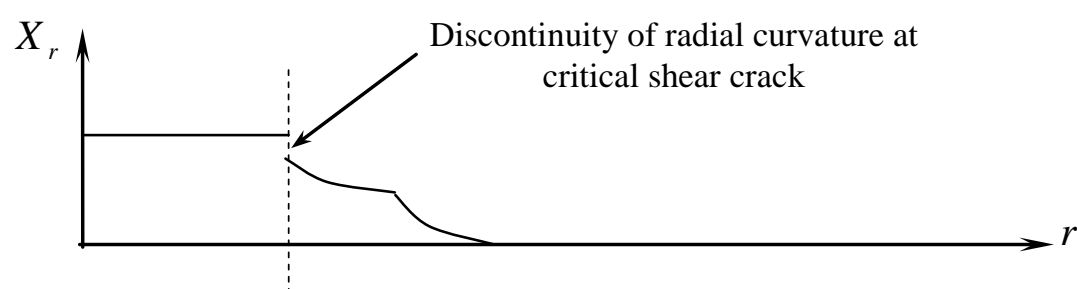

(b)

Fig. 8. Behaviour of slabs with low reinforcement ratios; (a) deformation shape; (b) distribution of radial curvature along the radius of the slab.

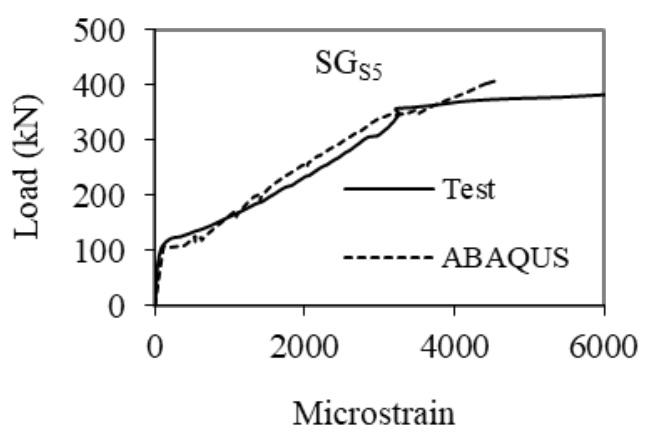

(a)

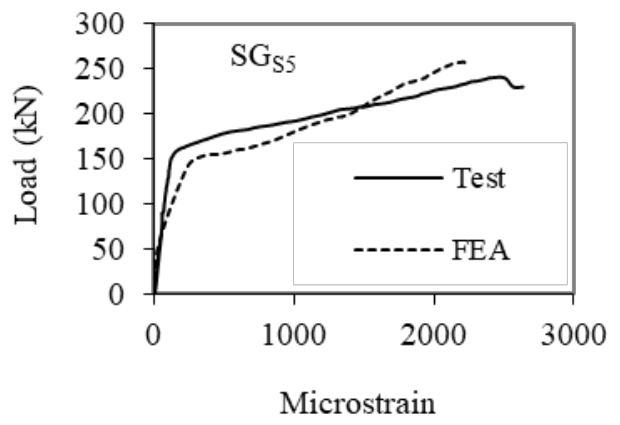

(c)

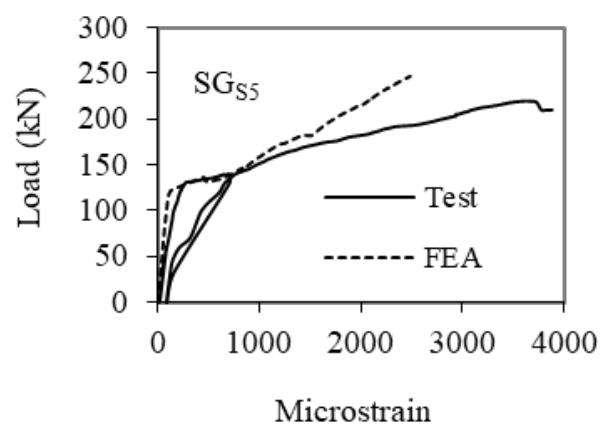

(b)

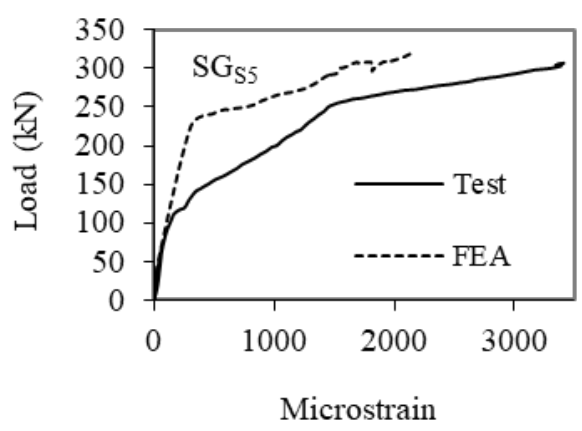

(d)

Fig. 9. Measurement of steel strains of the tested slabs: (a) slab RS-F $(b)$ slab RS-F; (c) slab RS-F 15 and (d) slab RS-F 30 . 


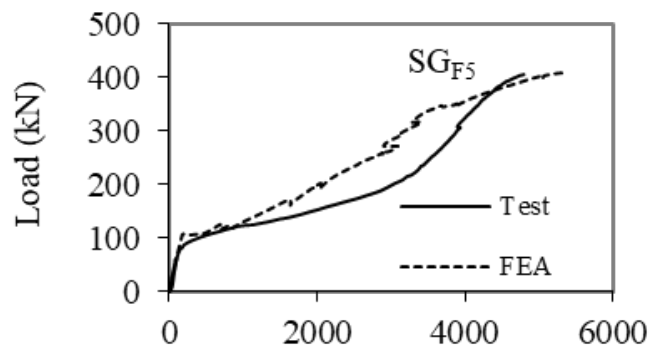

(a)

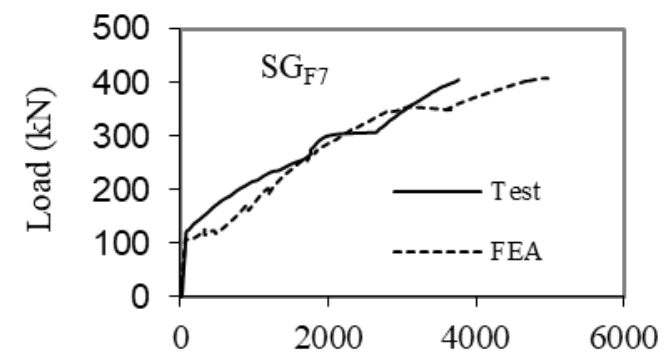

Microstrain

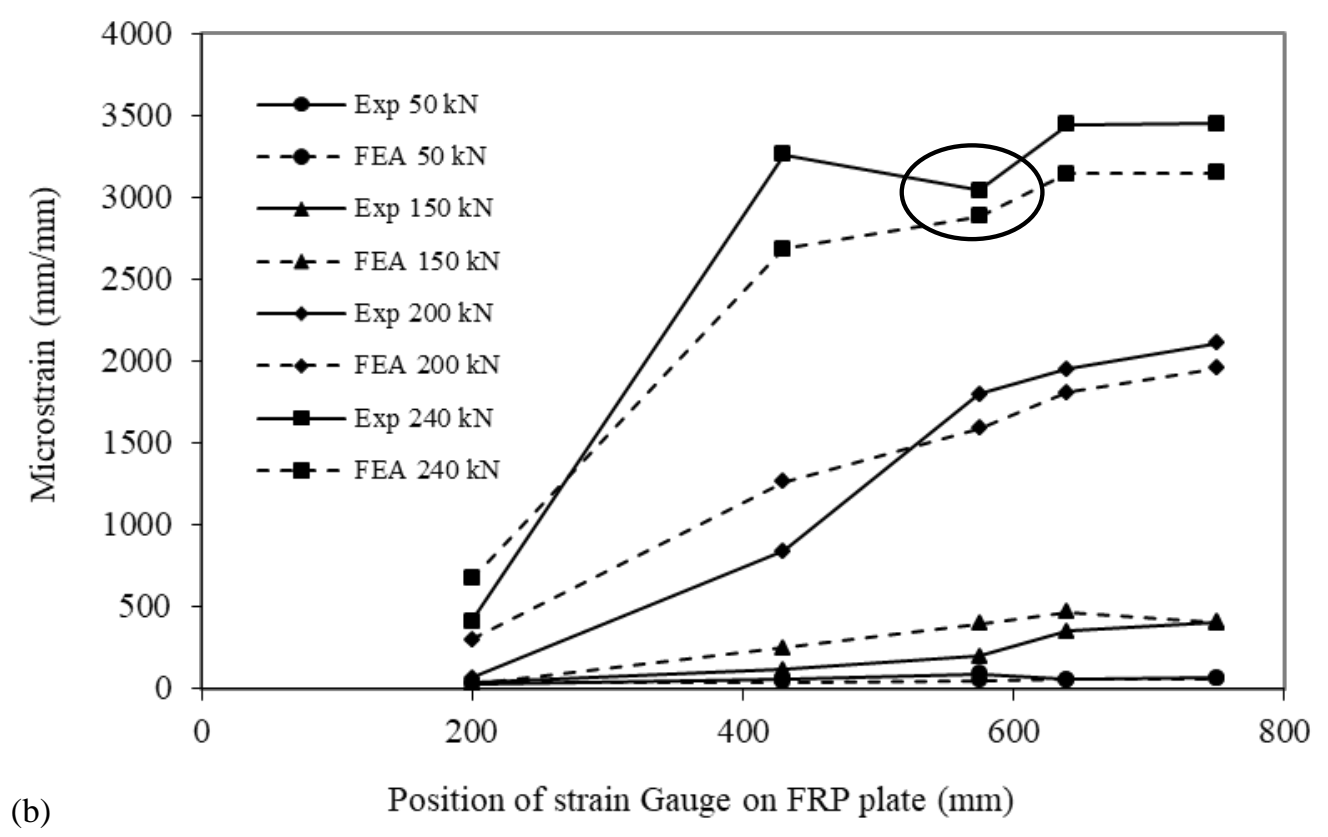

Fig. 10. Measurement of FRP strains of the tested slabs: (a) slab RS-F $F_{0}$; (b) slab RS-F 15 . 
(a)

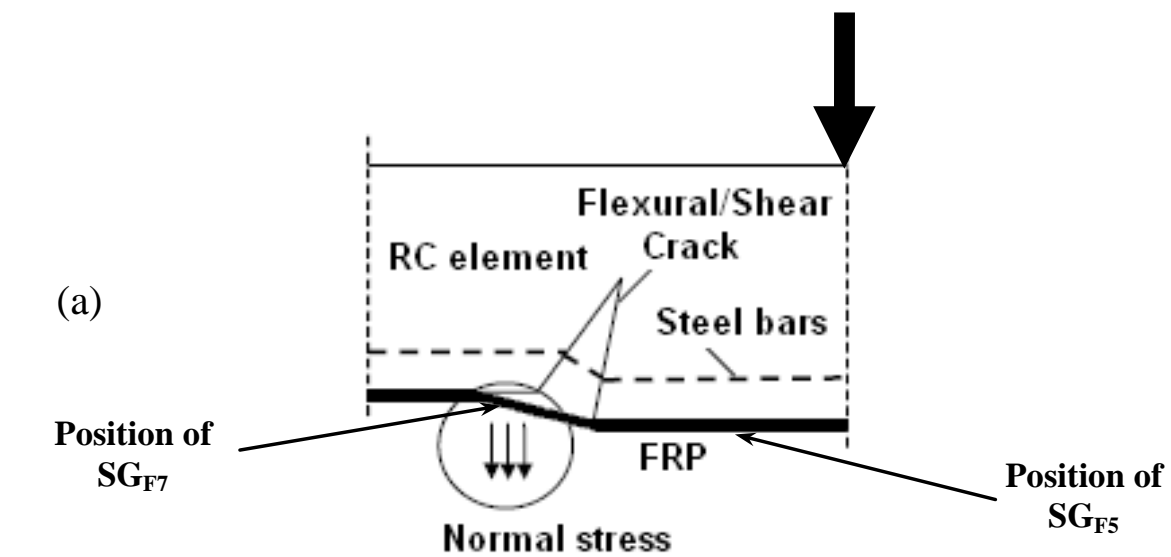

Slip field in interface element after crack

(b)

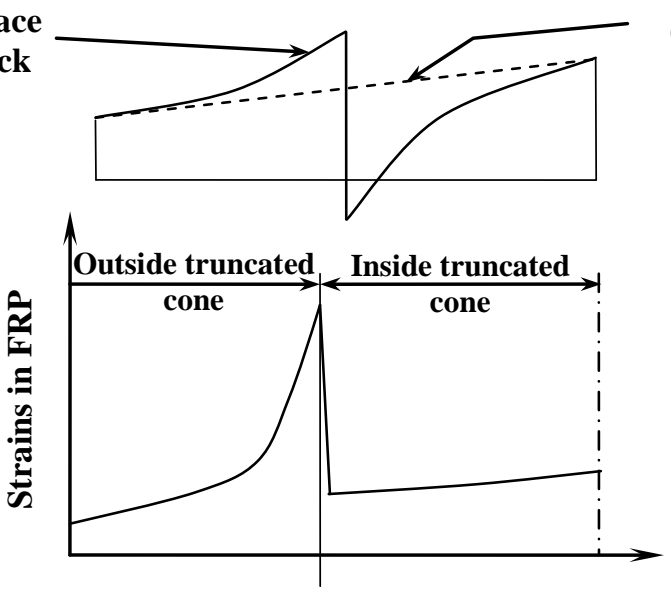

Slip field in interface element before crack

(c)

Distance along the member

Fig. 11. Flexural shear crack induced debonding; (a) schematic diagram for crack; (b) slip field at interface element; (c) interfacial shear stress distribution at crack. 

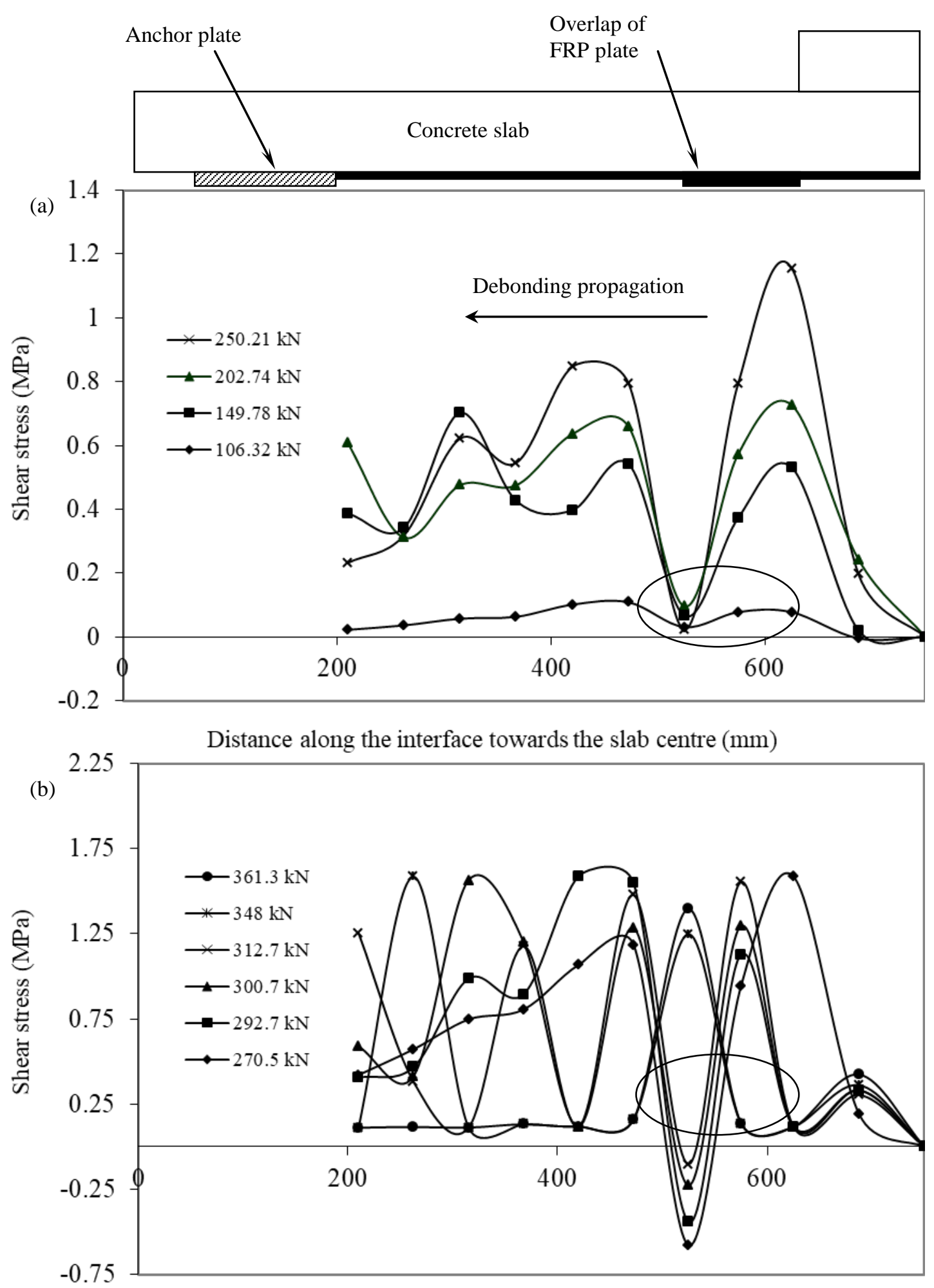

Distance along the interface towards the slab centre (mm)

Fig. 12. FRP-concrete interfacial behaviour of slab (RS-Fo): (a) before yielding; (b) after yielding. 

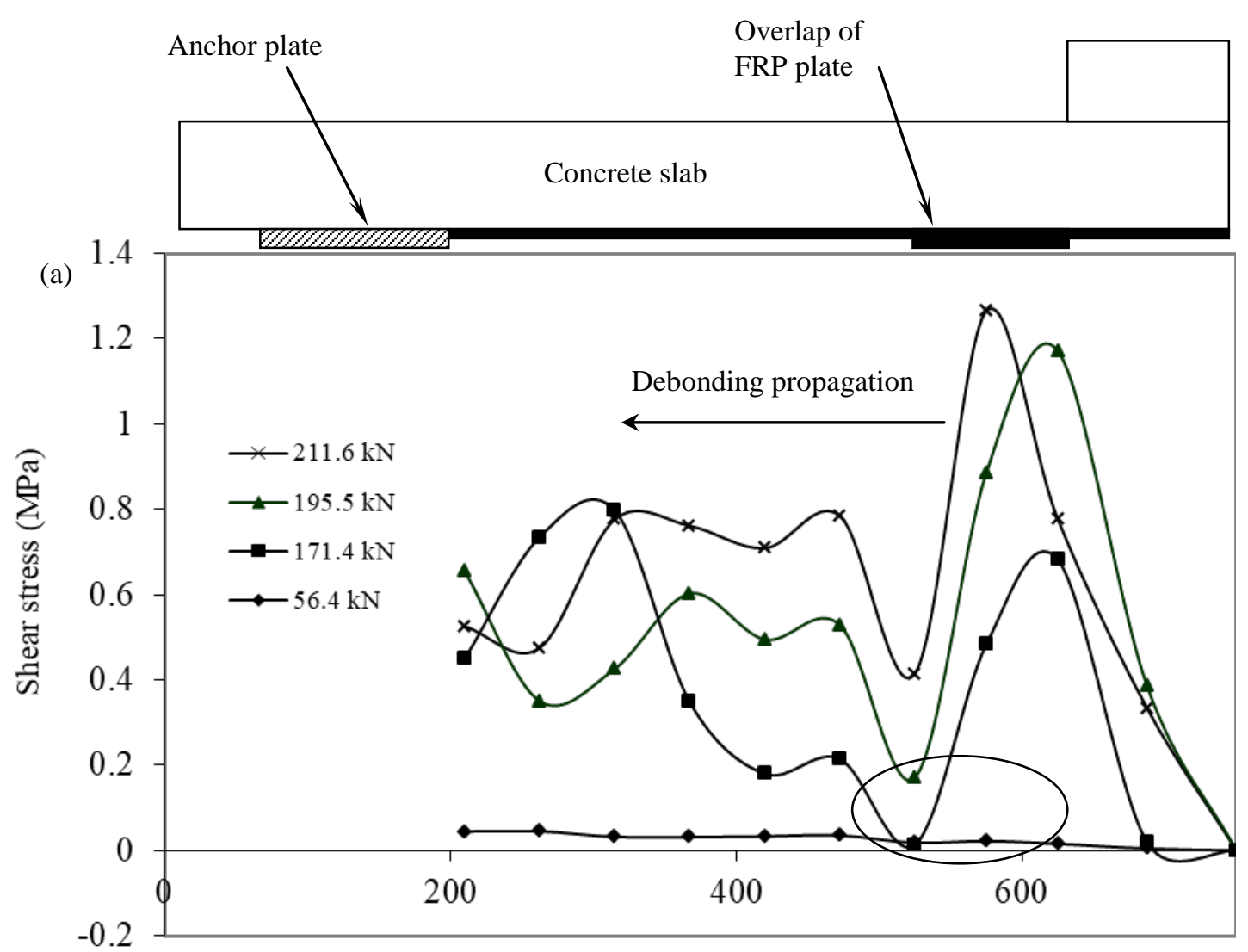

Distance along the interface towards the slab centre ( $\mathrm{mm})$

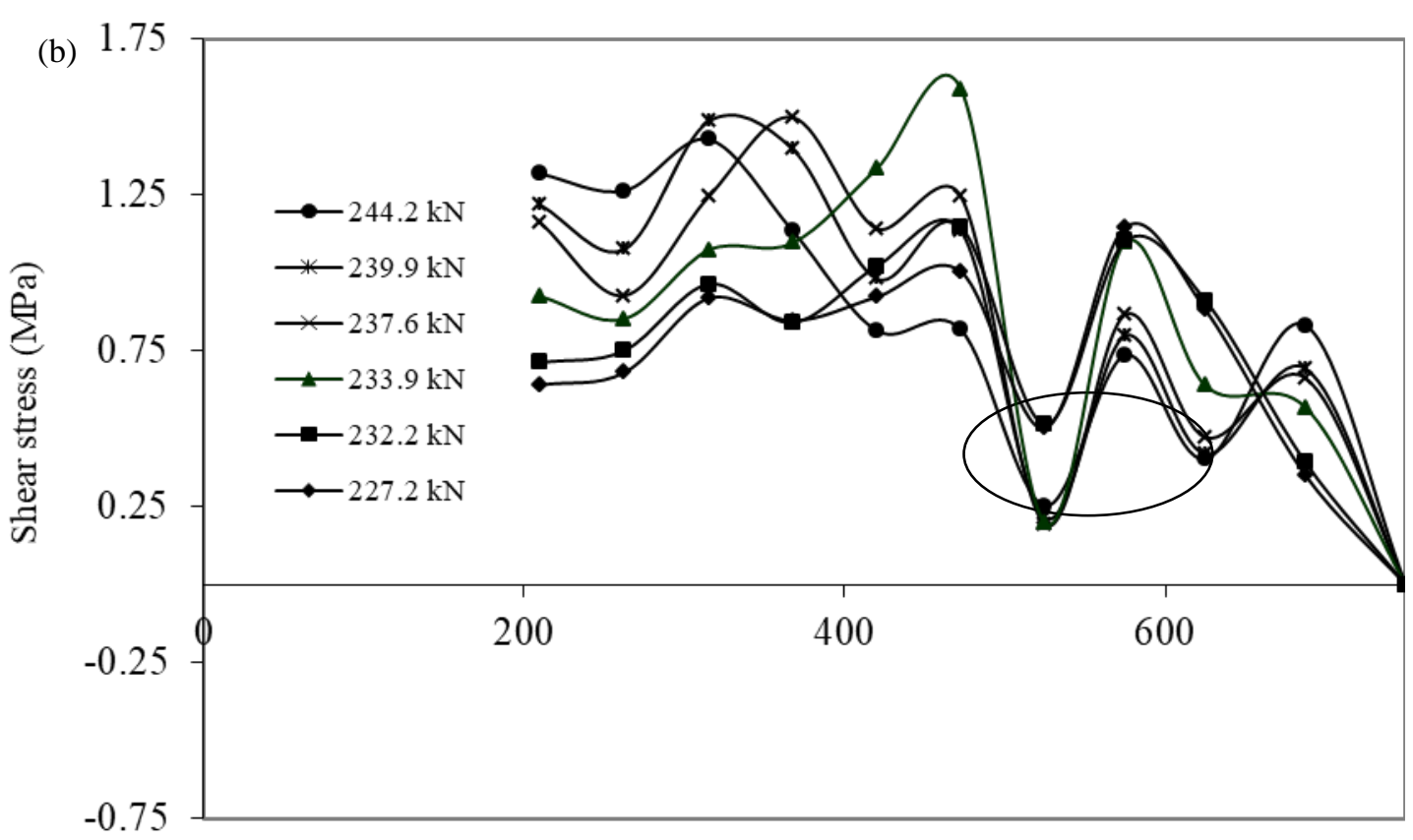

Distance along the interface towards the slab centre (mm)

Fig. 13. FRP-concrete interfacial behaviour of slab (RS-F 15$)$ : (a) before cracking; (b) later stages of loading. 

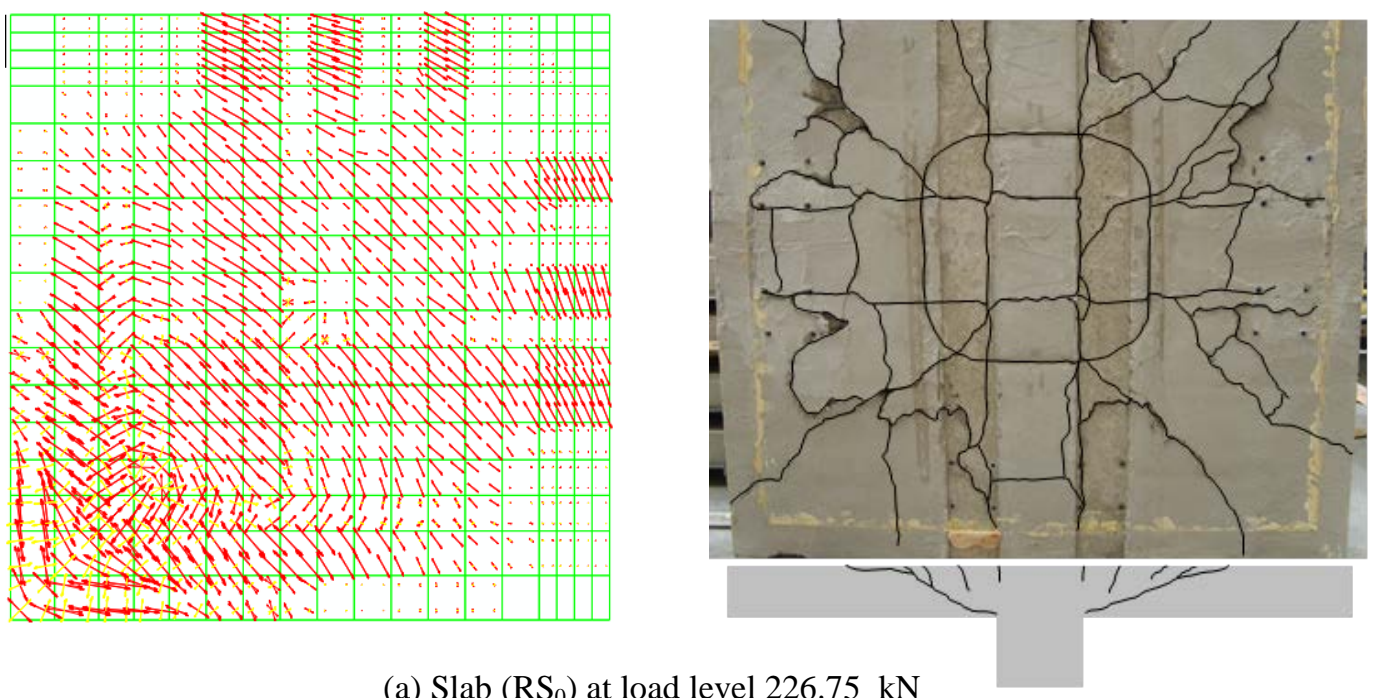

(a) Slab $\left(\mathrm{RS}_{0}\right)$ at load level $226.75 \mathrm{kN}$
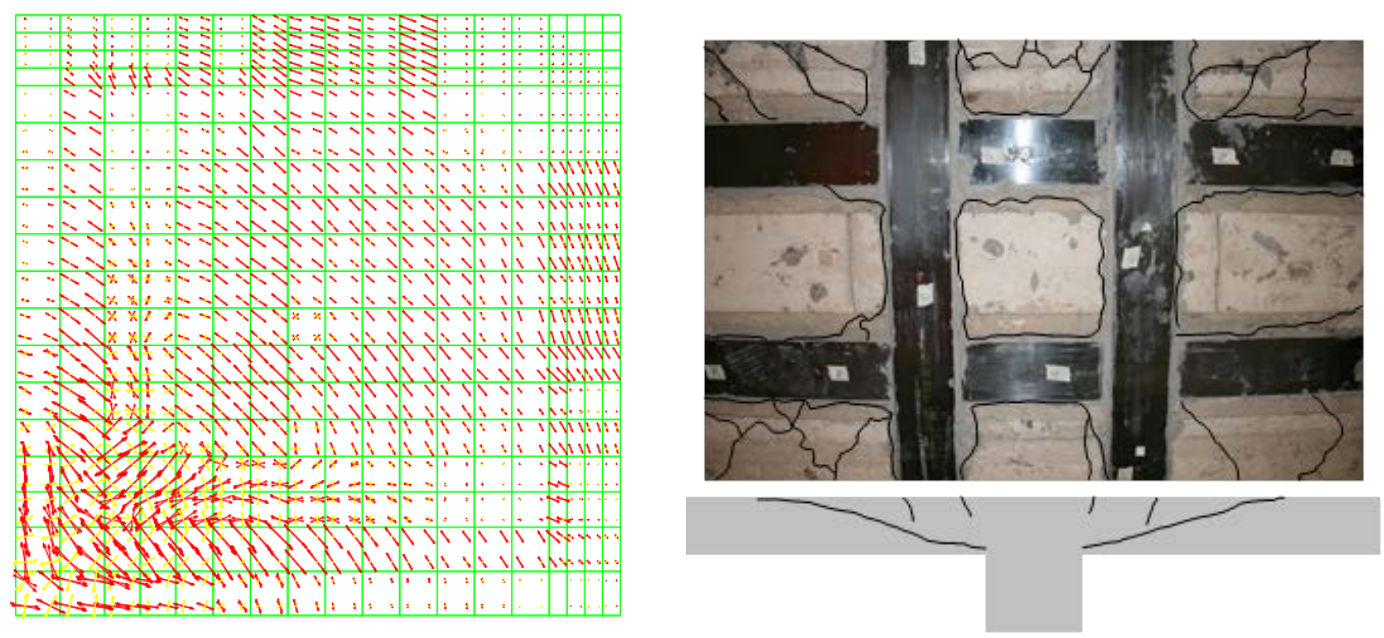

(b) Slab $\left(\mathrm{RS}-\mathrm{F}_{0}\right)$ at load level $372.7 \mathrm{kN}$

Fig. 14. Numerical prediction of crack pattern compared to tested slabs. 

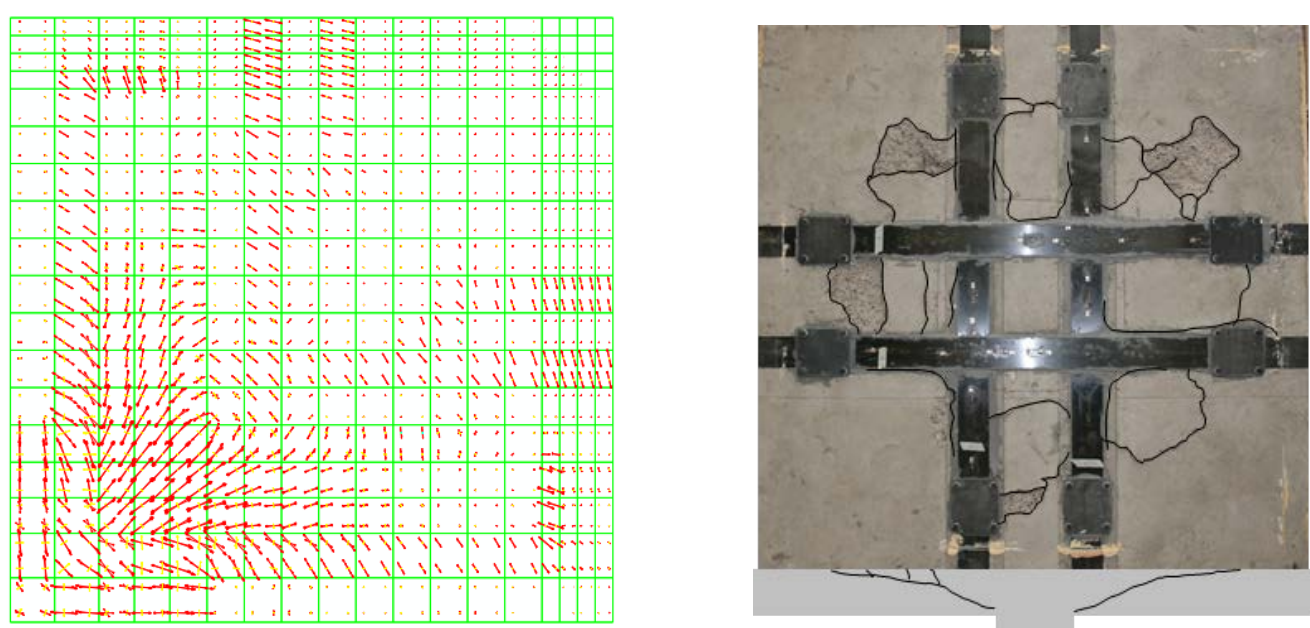

(c) Slab (RS-F F $\left._{15}\right)$ at load level $239.9 \mathrm{kN}$
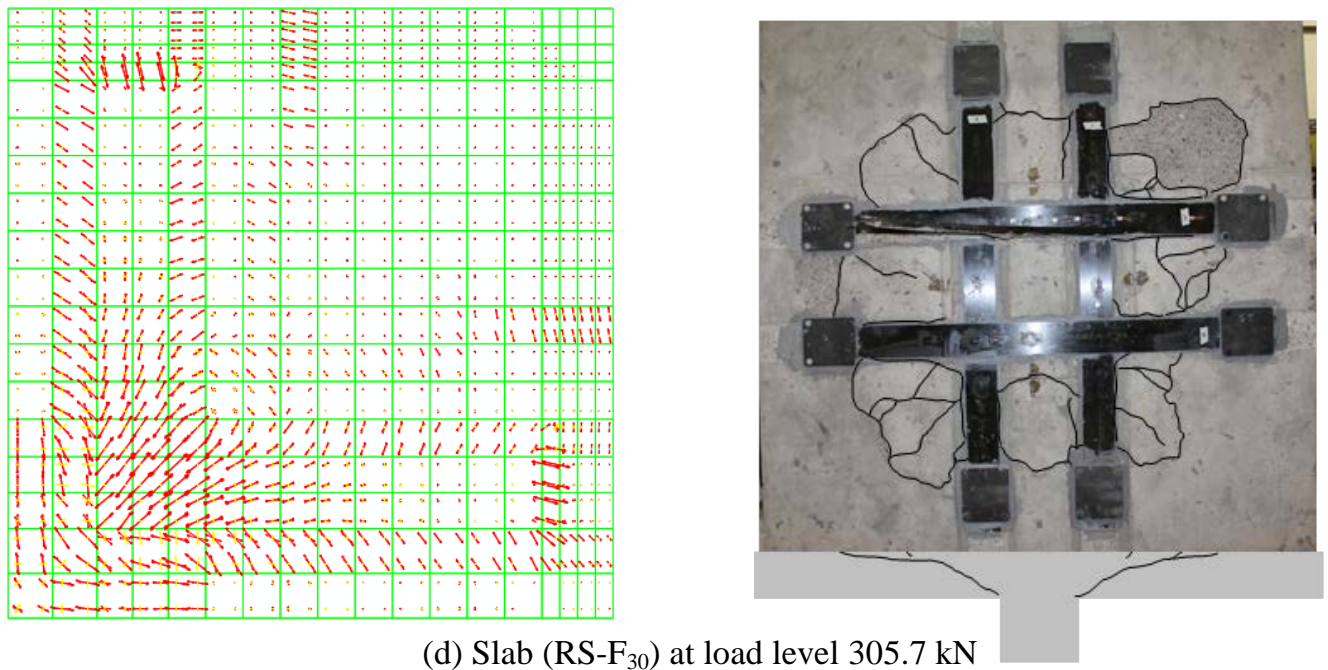

(d) Slab (RS- $\mathrm{F}_{30}$ ) at load level $305.7 \mathrm{kN}$

Fig. 14. Numerical prediction of crack pattern compared to tested slabs. 


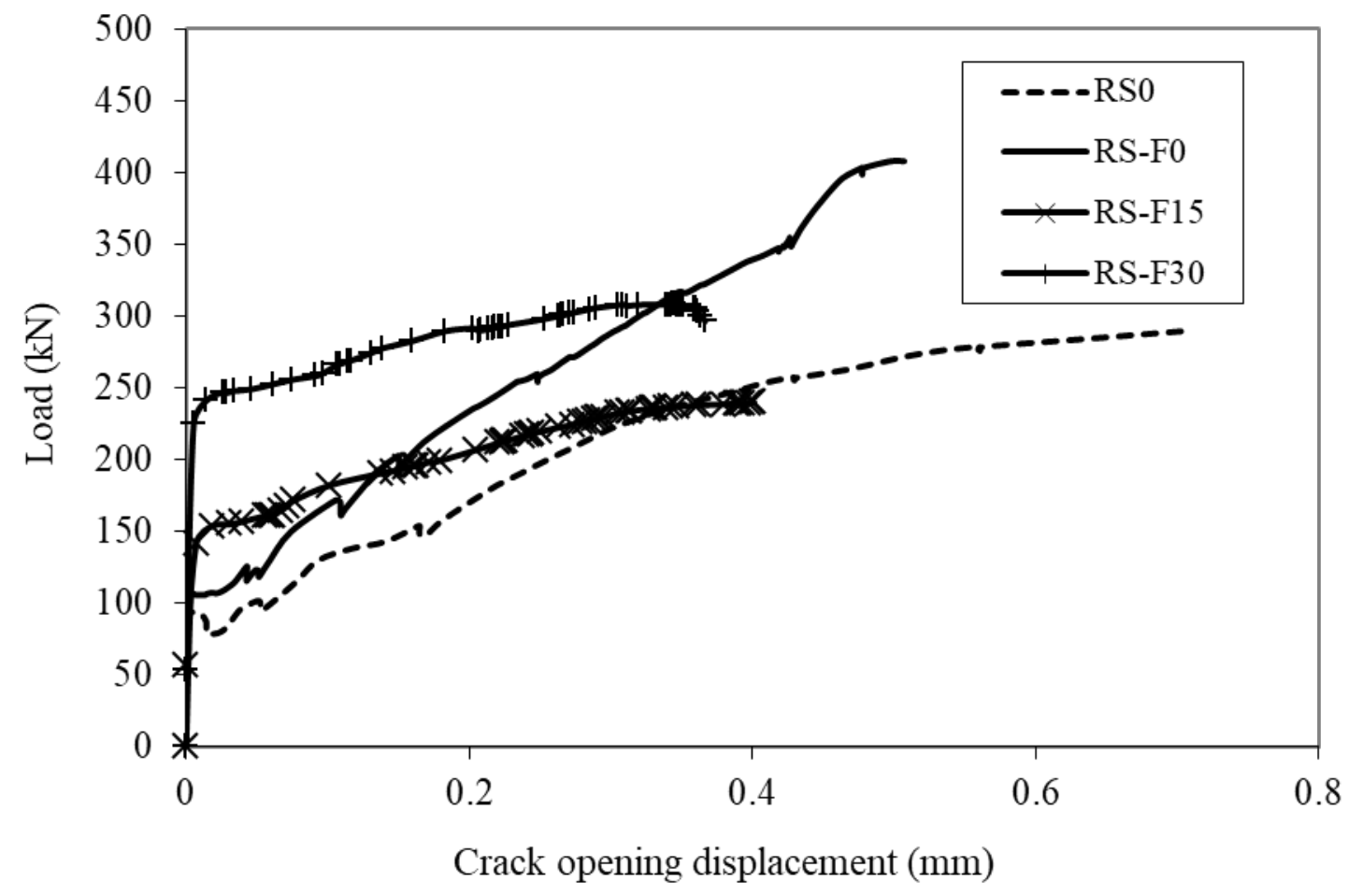

Fig. 15. Load-CMOD obtained at distance $1.5 \mathrm{~d}$ from the column face along the centreline of the slab. 


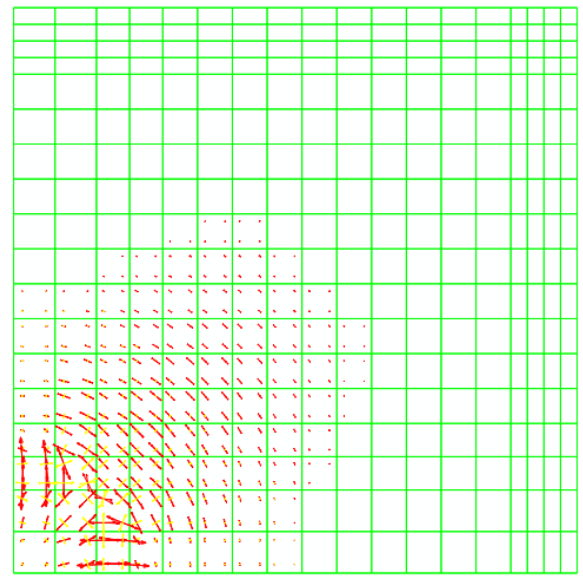

(a) predicted cracking load $91.5 \mathrm{kN}$.

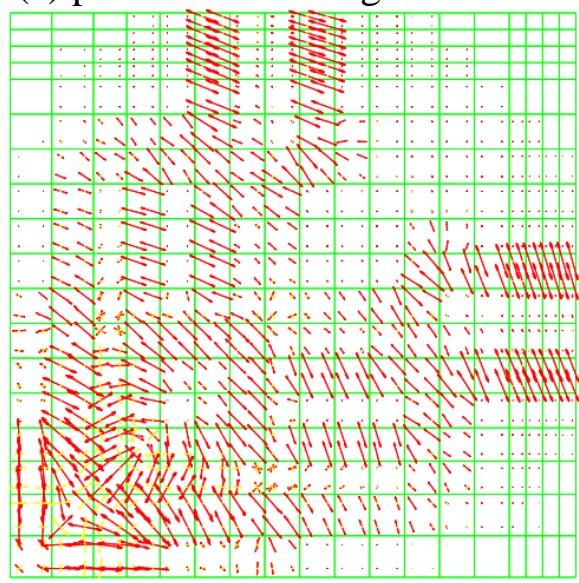

(c) predicted load $138.5 \mathrm{kN}$.

Fig. A-1. Predicted crack pattern of slab $\left(\mathrm{RS}_{0}\right)$ at different load levels.

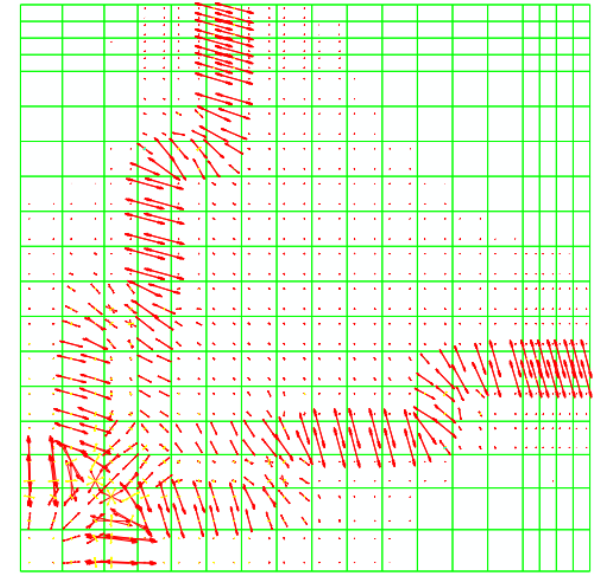

(b) predicted load $95.2 \mathrm{kN}$.

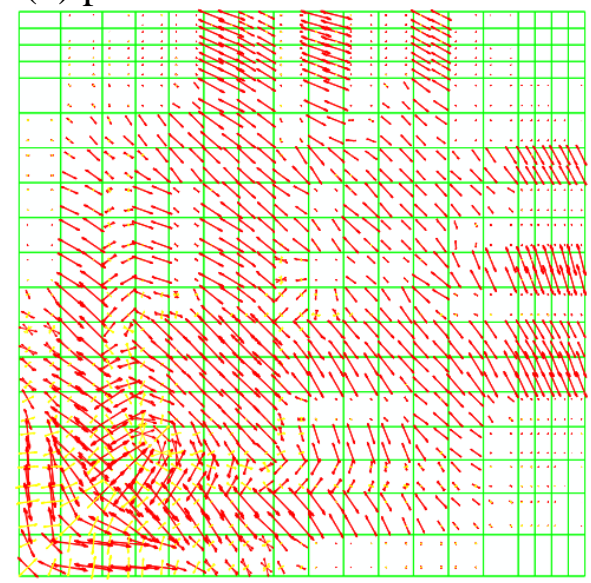

(d) predicted load $202.1 \mathrm{kN}$. 


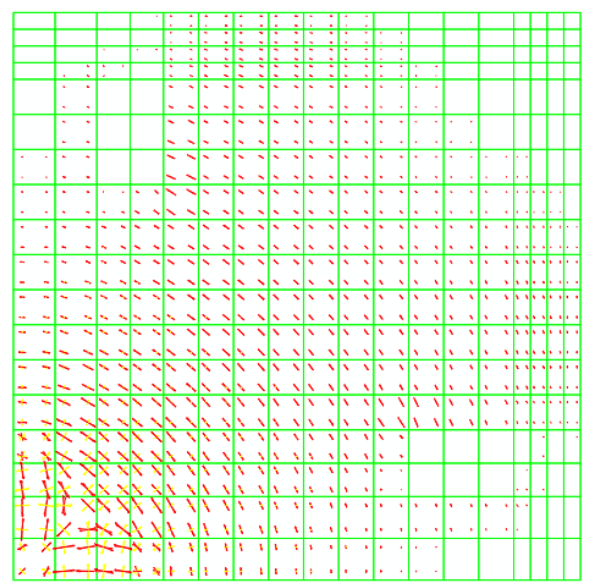

(a) predicted cracking load $106.3 \mathrm{kN}$.

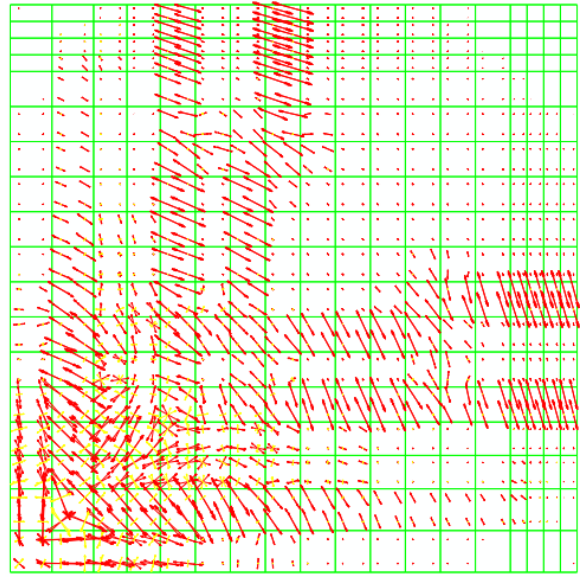

(c) predicted load $150.1 \mathrm{kN}$.

Fig. A-2. Predicted crack pattern of slab $\left(\mathrm{RS}-\mathrm{F}_{0}\right)$ at different load levels.

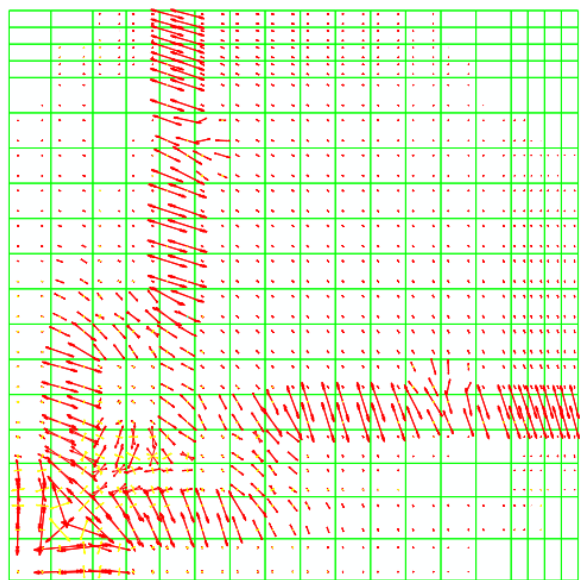

(b) predicted load $113.9 \mathrm{kN}$.

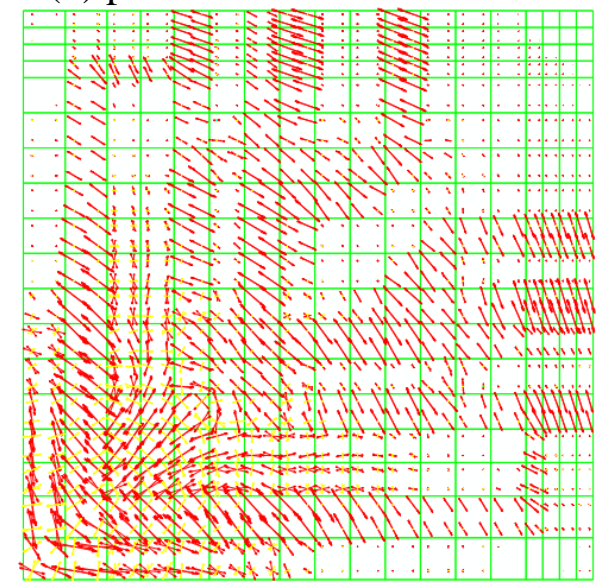

(d) predicted load $236 \mathrm{kN}$. 


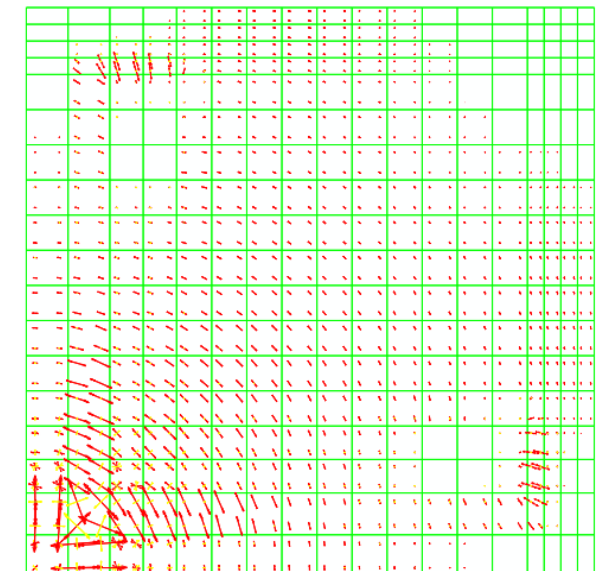

(a) predicted cracking load $141.7 \mathrm{kN}$.

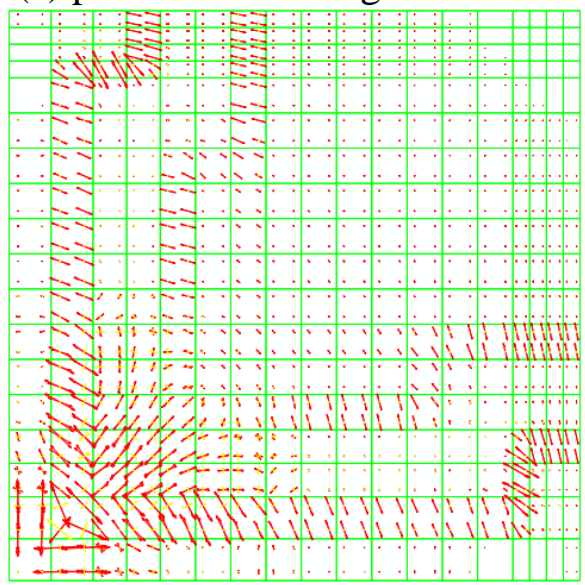

(c) predicted load $159.3 \mathrm{kN}$.

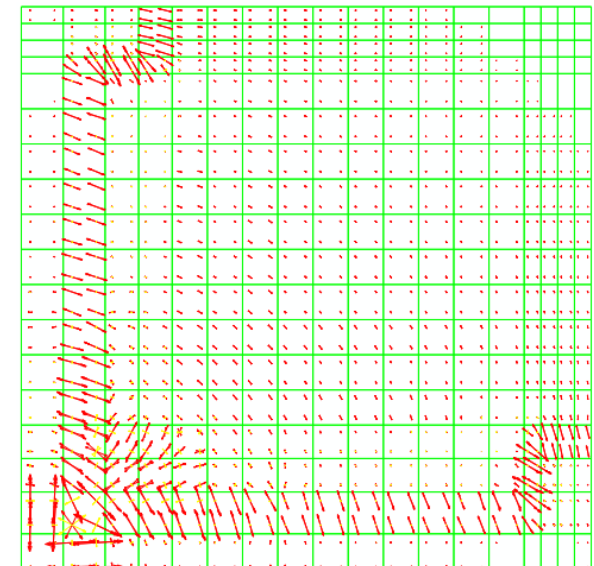

(b) predicted load $155.6 \mathrm{kN}$.

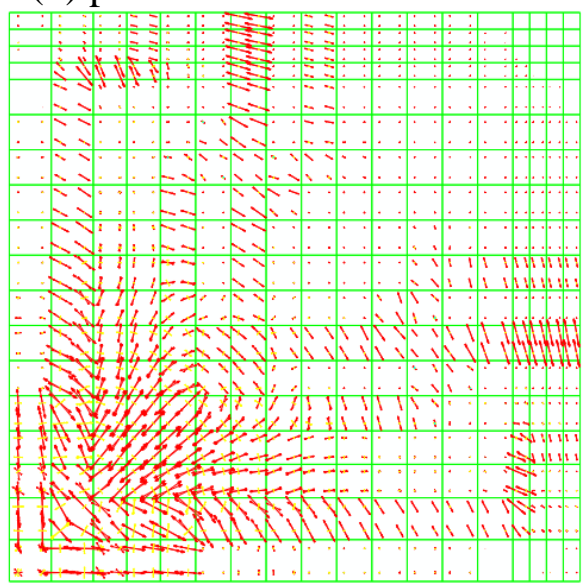

(d) predicted load $206.8 \mathrm{kN}$.

Fig. A-3. Predicted crack pattern of slab $\left(\mathrm{RS}-\mathrm{F}_{15}\right)$ at different load levels. 